\title{
UNGLASSIFIED
}

HW -40910

Chemistry - General

(M-3679, 17th Ed.)

\section{THE CHEMISTRY OF TRIBUTYL PHOSPHATE}

A REVIEW

By

L. L. Burger

Chemical Separations Unit

Chemical Research Sub-Section

\section{HANFORD ATOMIC PRODUCTS OPERATION \\ RICHLAND, WASHINGTON}

Work performed under Contract No. W-31-109-Eng-52 between the Atomic Energy Commission and General Electric Company

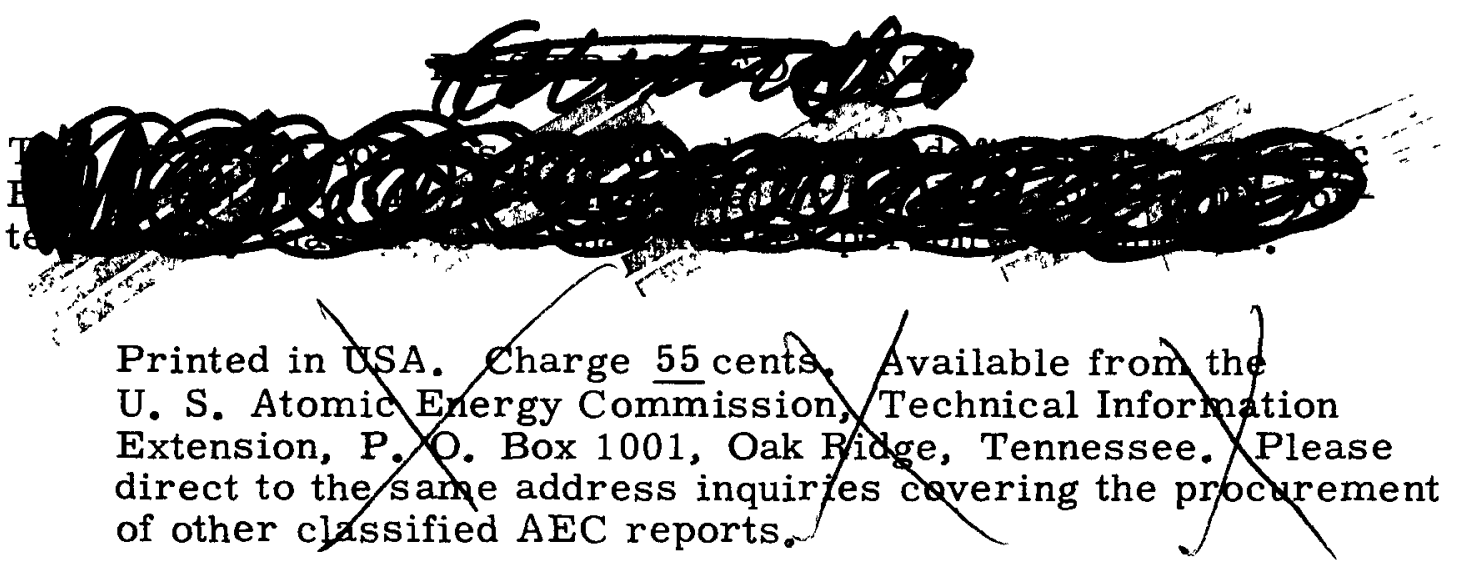

Classifieation cancelled (or changed to UNCLASSTFIED , )

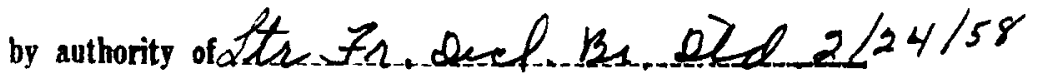

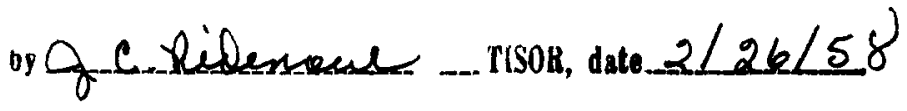

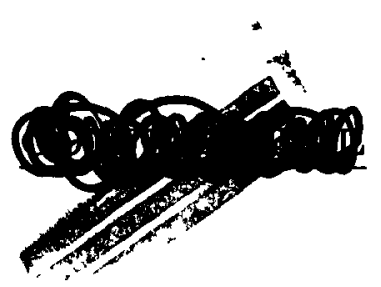




\section{DISCLAIMER}

This report was prepared as an account of work sponsored by an agency of the United States Government. Neither the United States Government nor any agency Thereof, nor any of their employees, makes any warranty, express or implied, or assumes any legal liability or responsibility for the accuracy, completeness, or usefulness of any information, apparatus, product, or process disclosed, or represents that its use would not infringe privately owned rights. Reference herein to any specific commercial product, process, or service by trade name, trademark, manufacturer, or otherwise does not necessarily constitute or imply its endorsement, recommendation, or favoring by the United States Government or any agency thereof. The views and opinions of authors expressed herein do not necessarily state or reflect those of the United States Government or any agency thereof. 


\section{DISCLAIMER}

Portions of this document may be illegible in electronic image products. Images are produced from the best available original document. 


\section{INTERNAL DISTRIBUTION}

\section{Copy Number}

$\begin{aligned} 1 & \text { F. W. Albaugh } \\ 2 & \text { E. L. Burley } \\ 3 & \text { R. E. Burns } \\ 4 & \text { R. J. Brouns } \\ 5 & \text { J. P. Duckworth } \\ 6 & \text { K. M. Harmon } \\ 7 & \text { M. K. Harmon } \\ 8 & \text { O. F. Hill } \\ 9 & \text { H. H. Hopkins, Jr. } \\ 10 & \text { E. R. Irish } \\ 11 & \text { R. H. Moore } \\ 12 & \text { R. L. Moore } \\ 13 & \text { G. C. Oberg } \\ 14 & \text { H. M. Parker } \\ 15 & \text { A. M. Platt } \\ 16 & \text { W. H. Reas } \\ 17 & \text { R. B. Richards } \\ 18 & \text { R. J. Sloat } \\ 19 & \text { R. E. Smith } \\ 20 & \text { R. E. Tomlinson } \\ 21 & \text { E. E. Voiland } \\ 22 & \text { M. T. Walling, Jr. } \\ 23 & \text { J. B. Work } \\ 24 & \text { L. L. Burger } \\ 25 & \text { 300 Files } \\ 26 & \text { 300 Files - Extra } \\ 27 & \text { COD, HAPO - Patent Branch, Washington } \\ 28 & \text { COD, HAPO - Responsible Reviewer, HAPO - } \\ 29-36 & \text { COD, HAPO - Declassification Branch, Oak Ridge } \\ & \text { Declassification Branch, Oak Ridge } \\ & \text { C. }\end{aligned}$

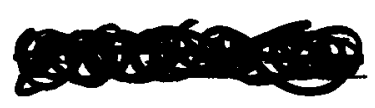


I. INTRODUCTION . . . . . . . . . . . . . . . 7

II. SUMMARY AND CONCLUSIONS ............... . . . 7

III. CHEMICAL PROPERTIES . . . . . . . . . . . . . 8

A. Thermal Stability ................. . 8

B. Oxidation. . . . . . . . . . . . . . . . . 9

C. Substitution Reactions ................. 11

D. Hydrolysis ................... . . 12

1. General ................ 12

2. Aqueous -Phase Hydrolysis .............. 15

a. Acid Hydrolysis .................. 15

b. Acid Hydrolysis with Uranium Present . . . . . . . 17

c. Alkaline Hydrolysis . . . . . . . . . . . . 21

3. Summary of Aqueous Phase Data for TBP . . . . . . . . 24

a. Relative Rates of Hydrolysis Steps . . . . . . . . . 24

b. Acid Strength . . . . . . . . . . . . 25

c. Nature of the Acid ................ 25

d. Uranium and Light ................. 26

e. The Alkyl Group . . . . . . . . . . . . . 26

f. Temperature ................ 26

4. Two-Phase Systems and Organic-Phase Hydrolysis . . 29

a. Anhydrous Dealkylation . . . . . . . . . . 29

b. Water Saturated TBP, Neutral Hydrolysis . . . . 29

c. Hydrolysis with Acid Present . . . . . . . . . . 30

d. Hydrolysis with Uranium Present . . . . . . . . 36

5. Summary of Organic-Phase Hydrolysis of TBP . . . . . 39

a. Acid Dependence .............. 39

b. Uranium ... . . . . . . . . . . . . . . 42

c. Temperature ................ 42

6. Other Products of Hydrolysis . . . . . . . . . . . 42

7. Hydrolysis of TBP Derivatives ............ 43

8. Mechanism of Hydrolysis ............. 45

a. Alkaline Hydrolysis . . . . . . . . . . . . . . 46

b. Acid Hydrolysis . . . . . . . . . . . . . . . 48

c. Neutral Hydrolysis ............. . 51

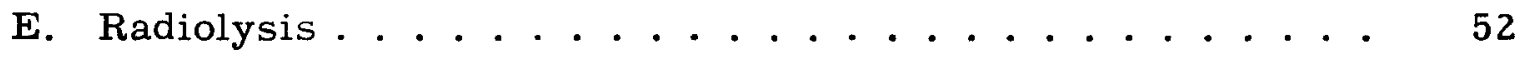




\section{TABLE OF CONTENTS (contd.)}

Page

IV. PROCESS SIGNIFICANCE . . . . . . . . . . . . 53

A. Water-Saturated TBP ............... 54

B. TBP in Contact with Nitric Acid-Uranyl Nitrate Solutions . . 54

C. Aqueous Acid Solutions . . . . . . . . . . . . . 55

D. Alkaline Solutions . . . . . . . . . . . . . 55

V. SUGGESTED STUDIES ................... 55

VI. APPENDIX....................... 57

A. Physical Properties . . . . . . . . . . . . . 57

B. Preparation of TBP and Other Phosphates ......... 61

1. Phosphorus Oxychloride Method ............ 61

2. Phosphorus Pentoxide and Alcohol ........... 61

3. Silver Phosphate Method . . . . . . . . . . . . . 61

4. Alkoxide Process . . . . . . . . . . . . . 63

5. Exchange Esterification .............. 63

6. Phosphorus Trichloride and Hydrocarbons . . . . . . . 63

7. Thermal Decomposition of Acid Phosphates . . . . . . 64

C. Purification ................. 64

D. Aqueous-Phase Hydrolysis of Other Phosphate Esters . . . 66 


\section{LIST OF TABLES}

$\underline{\text { Page }}$

I. Hydrolysis of TBP by Nitric Acid . . . . . . . . . . . . . 16

II. Hydrolysis Rate Constants of Butyl Phosphates in Aqueous Solutions.................... 18

III. Formation of DBP in RCU . . . . . . . . . . . . . 20

IV. Hydrolysis of TBP in Sodium Hydroxide Solutions . . . . . . . . 25

V. Summarized Rate Constants for the Aqueous Hydrolysis of TBP . 27

VI. TBP Hydrolysis as a Function of Temperature . . . . . . . . 32

VII. Organic Rate Constants Based on Unit Acid Concentration . . . 33

VIII. Formation of DBP in TBP . . . . . . . . . . . . . 37

IX. DBP Formation in TBP Diluent Mixtures . . . . . . . . . . . 39

X. Summarized Rate Constants for the Organic Phase Hydrolysis of TBP ...................... 40

XI. Hydrolysis of Tetrabutyl Pyrophosphate in Contact with Water . 44

XII. Physical Properties of TBP. . . . . . . . . . . . . . . 58

XIII. Vapor Pressure of TBP . . . . . . . . . . . . . . . . 58

XIV. Solubility of TBP in Aqueous Solutions at $25 \mathrm{C}$. . . . . . . . . 59

XV. Solubility of Water in TBP at $25 \mathrm{C}$. . . . . . . . . . . . . 59

XVI. Properties of Some TBP Impurities . . . . . . . . . . . . 62

$\mathrm{X}$ VII. Reactions of Phosphate Esters with Sodium Hydroxide and with

Sulfuric Acid .................... 68

XVIII. Hydrolysis of Ethyl Phosphates . . . . . . . . . . . . 71

XIX. Hydrolysis of Monoethyl Phosphate . . . . . . . . . . 71

XX. Hydrolysis of Isooctyl Phosphate in Potassium Hydroxide Solu-

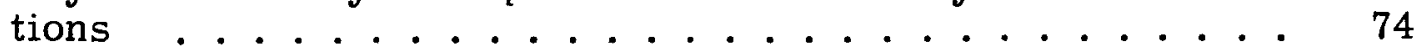

XXI. Rate Constants for the Aqueous Hydrolysis of Alkyl Phosphates . 75

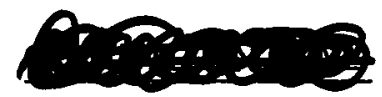




\section{LIST OF FIGURES}

Fig. No.

1 Selected Aqueous Phase Hydrolysis Rates . . . . . . . . . 14

2 Hydrolysis of TBP by 1 M Sodium Hydroxide . . . . . . . 22

3 Aqueous Hydrolysis of TBP (Uranyl Nitrate Solutions) . . . 23

4 Organic Phase Hydrolysis of TBP . . . . . . . . . . . 35 


\section{THE CHEMISTRY OF TRIBUTYL PHOSPHATE}

\section{A REVIEW}

\section{INTRODUCTION}

The attractiveness of tributyl phosphate, TBP, as a process solvent in uranium technology is due to some extent to its chemical inertness. Neither oxidizing nor reducing agents have an appreciable effect at room temperature and its resistance to hydrolysis is extremely high. However, a more detailed study under process conditions, particularly in radiation fields or at high temperatures, indicates that chemical reactions and, in particular, hydrolysis reactions may occur at a rate fast enough to be of concern. Further, the reaction products are particularly objectionable.

The literature on organo-phosphorus chemistry is quite extensive but widely scattered. Wright ${ }^{(1)}$ has made a literature survey of TBP as a uranium extractant and included some chemical properties. The reactions of phosphate esters reported in both unclassified and classified literature are to some extent in disagreement, particularly with respect to the kinetics. Thus it seemed desirable to review this work with the aim of determining and assembling the reliable information available and as a secondary aim to determine what further information is needed.

\section{SUMMARY AND CONCLUSIONS}

The preparation, purification and chemical properties of TBP have been reviewed with emphasis on the hydrolytic reactions. The latter is supplemented by data on other alkyl phosphates.

TBP is chemically a very stable compound as evidenced by its thermal stability and resistance to oxidation. The most important reactions are hydrolytic which cleave the butyl or butoxy group and normally produce butyl alcohol together with dibutyl and monobutyl phosphate (DBP and MBP, respectively), and eventually phosphoric acid.

(1) Wright, W. B., Critical Literature Survey of Tributyl Phosphate as a Uranium Extractant, Y-838, January 14, 1952. 
Hydrolysis occurs in either the organic phase or the aqueous phase and is first order with respect to the ester. Although the rate in the aqueous phase is much faster than in the organic phase, the solubility is so low in aqueous solutions that the organic phase reactions become more important. Acid hydrolysis depends on both the nature of the acid and the concentration. The order with respect to acid concentration is close to one but often less than one. Hydrolysis is catalyzed by both acids and bases. In the latter case, the reaction occurs only in the aqueous phase and normally stops with the formation of dibutyl phosphate.

The hydrolysis rate increases greatly as the temperature is rasied and an activation energy of the order of $20 \mathrm{kcal}$ is often found. The rates observed in the presence of $5 \mathrm{M}$ acid at 60 to $70 \mathrm{C}$ may be high enough to cause some concern in solvent extraction technology, since the product, dibutyl phosphate, has undesirable properties.

Impurities produced during manufacture or by thermal degradation during purification such as the pyrophosphates, if present, would yield the same objectionable products as TBP hydrolysis, but at a faster rate.

Included in the survey is a selected tabulation of physical properties of TBP.

Areas which need further investigation and clarification include (1) the relative hydrolysis rates of TBP, DBP and MBP in acid systems, (2) the effect on the hydrolysis of other components in solution, and (3) the mechanism of the hydrolytic reactions. Better analytical methods for DBP and MBP are also needed.

\section{CHEMICAL PROPERTIES}

A. Thermal Stability

TBP and other phosphate esters are quite stable thermally, but slow degradation does occur at temperatures somewhat above $100 \mathrm{C}$ as evidenced by odor and color formation. Aside from the distillation 
studies of Lane ${ }^{(2)}$ discussed in Section VI C, the reaction has apparently not been studied. Decomposition temperatures of acid phosphates and of some condensed phosphates are listed by Adler and Woodstock ${ }^{(3)}$, and are included in Table XVI.

B. Oxidation

Wagner found that TBP was stable toward $0.2 \mathrm{M}$ dichromate in $1 \underline{\mathrm{M}}$ nitric acid ${ }^{(4)}$, and dichromate has been found a useful reagent for determining butyl alcohol in $\mathrm{TBP}^{(5)}$. TBP is also relatively stable toward permanganate and treatment with potassium permanganate has been suggested as a purification method for alkyl phosphates ${ }^{(6)}$. Potassium permanganate in TBP will, however, slowly deposit manganese dioxide from solution after standing for a few days. (7)

The stability of TBP towards Ce(IV) is evidenced by its use by Warf as an extractant for cerium from nitric acid solutions ${ }^{(8)}$.

Work at Harwell indicated no sustained reaction between 60 per cent nitric acid and TBP at $60 \mathrm{C}$, even when an initial decomposition was started with high energy electrons ${ }^{(9)}$.

(2) Lane, E. S. , TBP Purification by Distillation over Alkalies, AERE C/M-140, Feb. 1952。

(3) Adler, H., Woodstock, W. H., Chem. Ind., 51, 516 (1942)

(4) Albaugh, F. W., Monthly Report, Applied Research Sub-Section, October, 1949, Nov. 15, 1949. HW-15074.

(5) Rider, B. F., Selected Analytical Methods for Purex Process Control KAPL-890, April 30, 1953.

(6) Clemmenson, E., U。S.Patent, Chem. Abs. 27, 3944 (1933).

(7) HAPO - unpublished work.

(8) Warf, J. C., Extraction of Ce (IV) Nitrate by Tributyl Phosphate, AECD-2524, Aug. 7, 1947.

(9) Author unknown - Exothermic Reaction Between TBP and Nitric Acid Systems, NP-4900, Sept. 1953. 
A vigorous reaction was considered possible only in the presence of a considerable amount of butyl alcohol.

Recent studies by $R$. H. Moore using nitric acid with added nitrous acid at $70 \mathrm{C}$ also failed to show any sustained reactions with tributyl phosphate. Under the same conditions, the hydrocarbon diluent underwent nitration and oxidation ${ }^{(10)}$. This observation that the diluent is much more subject to chemical degradation than TBP has been noted by others $(11),(12),(13),(14)$. At much higher temperatures, TBP does react with nitrates, occasionally with explosive violence. Comprehensive laboratory tests carried out with TBP-uranyl nitrate and nitric acid mixtures were reported by Colvin, Nichols and Siddall ${ }^{(15)}$ and showed:

(1) TBP-uranyl nitrate-nitric acid-water systems will react but not until the temperature has reached $135 \mathrm{C}$, the boiling point of 78 per cent uranyl nitrate hexahydrate.

(2) A high rate of temperature rise increases the chance of a reaction.

(3) Nitric acid-TBP-water will react violently if heated rapidly to greater than $150 \mathrm{C}$.

(4) TBP must be present to promote a noticeable exothermic reaction.

(10) Moore, R. H. Investigation of Solvent Degradation Products in Recycled Uranium Recovery Plant Solvent, HW-34502 Rev, April 28, 1955.

(11) Dawson, T. L., Lowe, A. R., Tri-n-butyl Phosphate as a Solvent, Parts 1 to 3 , RDBW-8048, April, 1953 .

(12) Solvent Degradation Meeting-ORNL, CF-52-8-8, Aug. 4, 1952.

(13) Technical Progress Letter-January, 1951, HW-19827.

(14) Quarterly Technical Progress Report-Savannah River Plant, January - March, 1954, DP-55 May, 1954.

(15) Colvin, T. J., Nichols, G. M., Siddall, T.H., TNX Evaporator Incident, January 12, 1953, Interim Technical Report-DP-25, May 15, 1953 . 
(5) Nitric acid aids the TBP-uranyl nitrate reaction.

(6) The reaction vigor increases as the ratio of TBP to uranyl nitrate increases.

(7) At high pressures, sustained reactions at lower concentrations are possible.

Subsequent work ${ }^{(16)}$ indicated that temperatures for rapid reactions between $\mathrm{TBP}$ and nitric acid were $160 \mathrm{C}$ for 22 per cent acid and $130 \mathrm{C}$ for 68 per cent acid, and that the presence of glass wool lowered the temperature required by 30 to $40 \mathrm{C}$.

At atmospheric pressure, Wagner was able to produce explosive reactions in TBP-uranyl nitrate systems only at temperatures of incipient calcination of the uranyl salt ${ }^{(17)}$.

No work has been reported on the air oxidation of TBP. The flash point ( Tag closed cup) of $145 \mathrm{C}^{(18)}$ corresponds to a vapor pressure of about $8 \mathrm{~mm}$ mercury, a slightly higher vapor concentration than required for hydrocarbons of equal molecular weight.

Summarizing, TBP is very stable towards oxidation. No

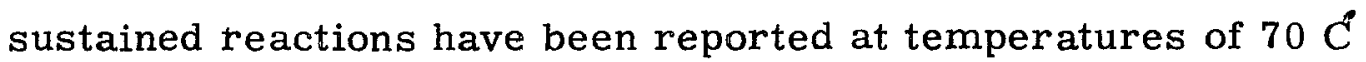
or below. TBP is stable towards nitrates at temperatures up to $135 \mathrm{C}$. At higher temperatures, violent decomposition may result probably as a result of nitration of the butyl groups.

C. Substitution Reactions

Lukovnikov ${ }^{(19)}$ using several different esters including TBP

(16) Reference (14), see also Savannah River Laboratory, TNX Semi-works Bi-Weekly Reports, April-June, 1953.

(17) Bushey, A. H. , Quarterly Progress Report, Chemistry Unit, January-February-March, 1953. HW-27727. April 30, 1953.

(18) Reactor Science and Technology, Vol。3, No. 1, March 1953, TID-2008, p. 122 .

(19) Lukovnikov, A. F., et al, Doklady Akad. Nauk USSR 70, 43 (1950), Chem. Abs. 44, 4315. 
found no exchange with disodium phosphate after 20 to 30 hours at 100 to $300 \mathrm{C}$. Dioxane was employed as a solvent. In phosphoric acid, exchange does occur. Baldwin and Higgins $(20)$ found that phosphorus -32 initially in phosphoric acid exchanged with TBP when heated at $170 \mathrm{C}$ for a few hours. P-32 was found in the TBP as well as in DBP and MBP fractions.

Exchange of alkyl groups between alcohols and alkyl phosphates occurs readily inder certain conditions. This reaction is discussed in Section VIB. The labile nature of the alkyl group is illustrated by the reaction of TBP with benzene in the presence of aluminum chloride to yield butyl benzene and $\mathrm{DBP}^{(21)}$. As another example, triethyl phosphate was employed by Ropp ${ }^{(22)}$ to synthesize $\mathrm{C}^{14}$-labelled ethyl acetate from sodium acetate.

D. Hydrolysis

1. General

As esters, a fundamental aqueous phase reaction of organic phosphates should be cleavage of the P-O-C linkage, catalyzed by either acids or bases to give alcohol and the partially substituted phosphoric acid and eventually ortho-phosphoric acid. The hydrolytic reactions are the most important reactions which occur, and it is well to examine the general nature of this process. The hydrolysis of esters of carboxylic acids has been studied in detail by Lowry ${ }^{(23)}$, Ingold ${ }^{(24)}$ and others. This reaction generally leads to fission of the acetyl carbon bond (analogous to the P-O bond). Blumenthal and

(20) Baldwin, W. H., Higgins, C. E., Chem Div., Semi Annual Progress Report, ORNL 1674, p. 53. Dec. 20,1953 .

(21) Behrman, Lowry, T., J. Am. Chem. Soc. 60, 2596 (1938).

(22) Ropp, G. A., J. Am. Chem. Soc. 72, 2299 (1950).

(23) Lowry, T., J. Chem. Soc., 1925, 127, 1380.

(24) Ingold, C. K., Structure and Mechanism in Organic Chemistry, Cornell Univ. Press, Ithaca, N. Y., (1953). 
Herbert ${ }^{(25)}$, studying the acid hydrolysis of trimethyl phosphate, found instead that greater than 70 per cent of the decomposition was through the $\mathrm{O}-\mathrm{C}$ bond rupture. They pointed out that the reaction could more truly be called de-alkylation rather than hydrolysis.

In this respect, the reaction resembles the cleavage of esters with dry halogen acids. Thus Gerrard, Green and Nutkins ${ }^{(26)}$ obtained excellent yields of alkyl halide and dialkyl phosphate using dry hydrogen chloride, hydrogen bromide or hydrogen iodide on tertiary phosphates. This aspect of the reaction is of particular interest, since, as the size of the alkyl group increases, the solubility in water becomes very small and the reactions in the organic phase become more important. Alkaline hydrolysis, on the other hand, appears to occur by fission of the $\mathrm{P}-\mathrm{O}$ bond as demonstrated by Blumenthal and Herbert ${ }^{(25)}$.

Considerable information is available on the lower alkyl phosphates as a result of their biological interest. These include methyl and ethyl phosphates as well as glycerophosphates, alkoxyphosphates and substituted aryl phosphates. A discussion of this work appears in Section VI D. These compounds, largely aqueous soluble, can offer support in the prediction or interpretation of reactions of the similar molecule, TBP. Selected data are shown in Figure 1.

Pertinent conclusions from the survey of the lower esters include: (1) the hydrolysis is first order with respect to the ester, (2) the triester hydrolyzes 10 to 50 times faster than the diester, (3) in strong acid the hydrolysis rate is greatly

(25) Blumenthal, E., Herbert, J. B. M., Trans. Faraday Soc., 41,611 (1945).

(26) Gerrard, W., Green, W. T., Nutkins, R. A., J. Chem. Soc., 1952, 4076. 


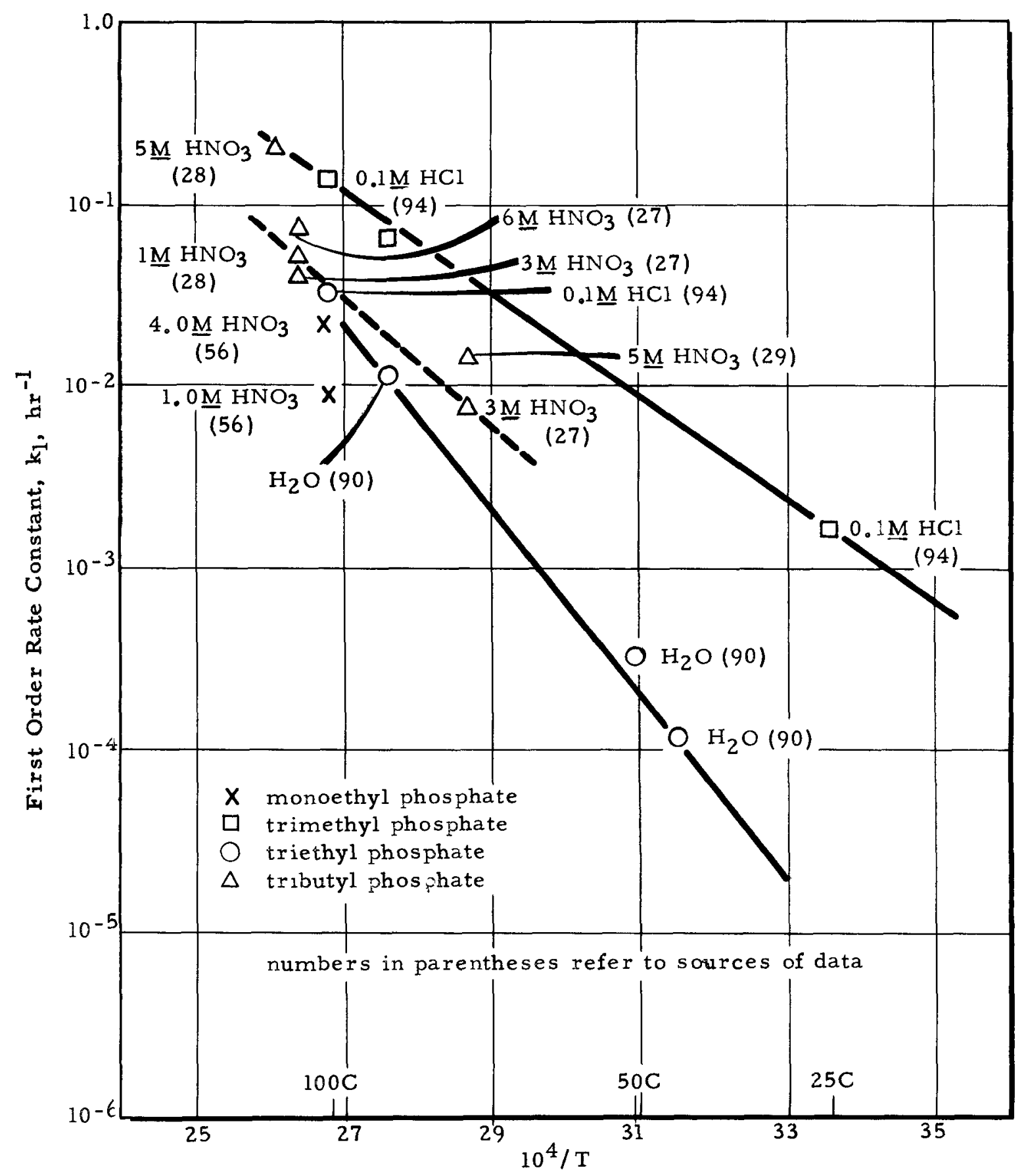

FIGURE 1

SELECTED AQUEOUS PHASE HYDROLYSIS RATES 
increased, (4) in strong bases the hydrolysis usually stops at the diester, but occurs at roughly the same rate as acid hydrolysis, (5) in the "neutral" region the rate is very $\mathrm{pH}$ dependent, at least for the monoalkyl phosphates and probably for dialkyl phosphates.

The following points must be viewed with considerable uncertainty: (1) in acid solution the monoester hydrolyzes slightly faster than the diester, (2) the resistance to hydrolysis increases with the size of the alkyl group. Only the methyl and ethyl derivatives unambiguously support this often-stated generality. The hydrolysis of disopropyl phosphate, for example, is somewhat faster than that of diethyl phosphate. (See Table XVII).

With the higher alkyl esters, the first and second hydrolysis products are much more water soluble than the parent ester. Thus aqueous phase reactions as well as those occuring in organic solutions are of interest, and it is of value to consider them separately.

\section{Aqueous Phase Hydrolysis of TBP}

The information on TBP hydrolysis comes completely from classified sources. The work on this problem has been plagued by the difficulties of working at the low concentrations defined by the solubilities, and the analytical problem of determining the individual hydrolysis products. The situation is made worse by the tendency to examine only that small facet of the problem that deals with a specific plant process, thus providing no comparative basis for the multitude of data.

The available information will be discussed as acid hydrolysis or alkaline hydrolysis.

a. Acid Hydrolysis

The earliest study of this system was that of Wagner ${ }^{(27)}$

(27) Wagner, R. M., The Hydrolysis Products of Tributyl Phosphate and Their Effects on the Tributyl Phosphate Process for Uranium Recovery, HW-19959, April 15, 1951. 
who investigated the rate of hydrolysis of monobutyl phosphate (MBP) and dibutyl phosphate (DBP) in $3 \mathrm{M}$ nitric acid at $76 \mathrm{C}$. Writing the reaction as

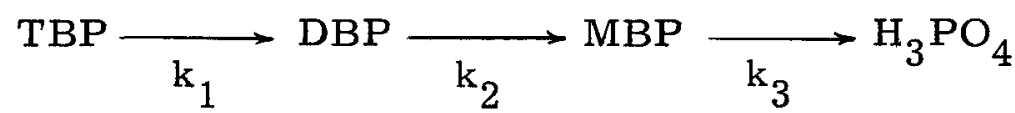

his experiment with MBP gave a first order rate constant, for $\mathrm{k}_{3}$ of $1.6 \times 10^{-3} \mathrm{hr}^{-1}$. The experiment with DBP gave a value for $\mathrm{k}_{2}$ of $3.4 \times 10^{-3} \mathrm{hr}^{-1}$. However, the data given for the DBP experiment do not confirm the previous value of $\mathrm{k}_{3}$ but indicate that a value of about $2 \times 10^{-4} \mathrm{hr}^{-1}$ is needed. In view of the poor material balance indicated by the analytical data, one is inclined to disregard the experiment using DBP. His reported values for $\mathrm{k}_{3}$ of $1.6 \times 10^{-3} \mathrm{hr}^{-1}$ at $76 \mathrm{C}$ and $1.0 \times 10^{-5} \mathrm{hr}^{-1}$ at $25 \mathrm{C}$ are more likely to be correct. The activation energy found for this reaction was $11.4 \mathrm{kcal}$.

The hydrolysis of TBP was also studied by Wagner (27). He employed a two phase system with $3 \mathrm{M}$ and $6 \mathrm{M}$ nitric acid at $76 \mathrm{C}$ and $105 \mathrm{C}$ and phase volume ratios (aq/org) of 1 and 200 with results listed in the following table:

TABLE I

THE HYDROLYSIS OF TBP BY NITRIC ACID

Aqueous Phase: 3 or 6 M Nitric Acid

Organic Phase: $100 \%$ TBP

Temperature, ${ }^{\circ} \mathrm{C}$

105

76

25

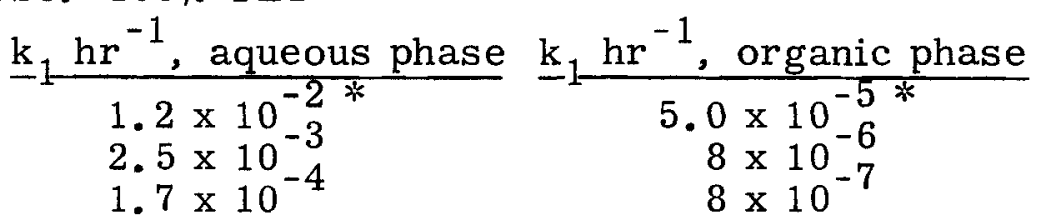

* Wagner's rate constants are expressed per mole of acid assuming first order acid dependence. 
His calculation at $105 \mathrm{C}$ involved expansion of an exponential which is invalid for the magnitude of the variables employed. However, more fundamental questions are raised by his assumption that the rate-determining step is the hydrolysis of TBP to DBP and by his conclusion that a determination of MBP and $\mathrm{H}_{3} \mathrm{PO}_{4}$ represented the TBP decomposed. DBP was never determined. His observation of an induction period further complicates the interpretation. (It seems probable then that the data in Table I do not actually represent step one in the hydrolysis of TBP.)

Lanham and Reilly ${ }^{(28)}$ reported 10 per cent hydrolysis in the aqueous phase at the boiling point after $0.35,0.55$ and 1.9 hours with 8.6, 5.4 and 1.04 M nitric acid, respectively. Approximate $\mathrm{k}_{1}$ values from their data are $0.28 \mathrm{hr}^{-1}, 0.19 \mathrm{hr}^{-1}$, and $0.056 \mathrm{hr}^{-1}$, respectively. At $60 \mathrm{C}$ in $5.4 \mathrm{M}$ acid, a value of 2.9 per cent in 24 hours was found, or a value for $\mathrm{k}_{1}$ of $1.2 \mathrm{x}$ $10^{-3} \mathrm{hr}-1$.

Baldwin and Higgins ${ }^{(29)}$ in a single phase study with $5 \underline{\mathrm{M}}$ nitric acid found a value for $\mathrm{k}_{1}$ of $0.014 \mathrm{hr}^{-1}$ at $75 \mathrm{C}$. They also reported that the use of $5 \mathrm{M}$ hydrochloric acid gave a hydrolysis rate four to five times faster than that with $5 \mathrm{M}$ nitric acid. These data are summarized in Table V. Both of the studies at Oak Ridge employed P-32 as a tracer and the analytical results are probably better than the previously discussed work. These data indicate that the TBP decomposition is first order and do not show the induction period reported by Wagner.

b. Acid Hydrolysis with Uranium Present

Measurements of DBP in systems containing uranyl nitrate were

(28) Reilly, V. J., The Hydrolysis of Tributyl Phosphate and its Effect on the Purex Process, ORNL-1138, Dec. 13, 1951.

(29) Baldwin, W. H., Higgins, C. E., ChemistryDivision Quarterly Progress Report for Period ending June, 1951. ORNL-1116. Feb. 14, 1952. 
made by Brite. ${ }^{(30)}$ TBP and DBP were added to $6 \underline{\mathrm{M}}, 2 \underline{\mathrm{M}}$ and $0.2 \mathrm{M}$ nitric acid solutions containing $0.11 \mathrm{M}$ uranyl nitrate. The following rate constants were computed for the reactions at the reflux temperature.

TABLE II

HYDROLYSIS RATE CONSTANTS OF BUTYL PHOSPHATES IN AQUEOUS SOLUTION Temperature - Reflux, 0.11 M UO $2\left(\mathrm{NO}_{3}\right)_{2}$ Light not Excluded

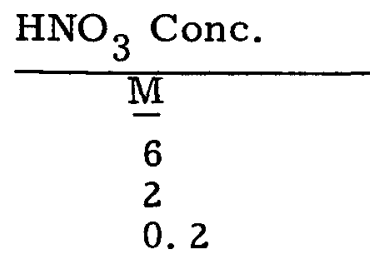

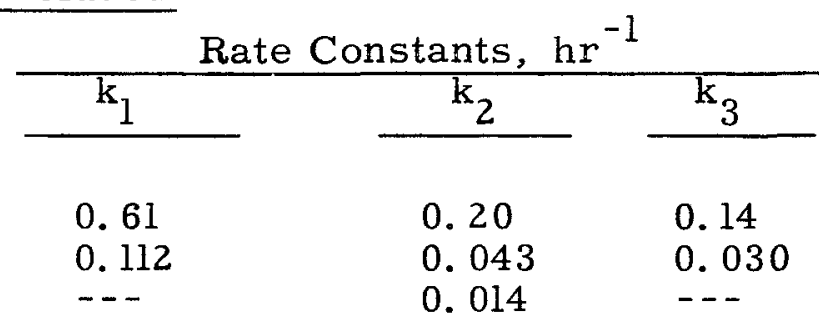

As can be seen from Table II, these values are considerably higher than those found by others for pure nitric acid solutions. The reactions were not protected from the light and thus, as pointed out by Brite, the known photochemical effect in uranium systems may make the rates high in this experiment. Later work by Brite has confirmed this. (31) Solutions containing $0.25 \mathrm{M}$ uranyl nitrate, $0.05 \mathrm{M}$ nitric acid were shaken with 20 per cent TBP in Shell Spray Base and the phases separated. The rates of DBP buildup at $25 \mathrm{C}$ were followed with (a) samples exposed to laboratory light, (b) samples in amber colored bottles, and (c) samples in the dark. In three to four days the DBP concentration in (a) reached a maximum of $19 \mathrm{mg}$ per liter, then dropped rapidly. In (b) and (c) a very slow buildup of DBP was observed over the ten day experiment. Assuming the solubility of TBP in a 20

(30) Bushey, A. H. , Quarterly Progress Report, Jan., Feb. , March, 1954, HW-31630, p. 61, May 1, 1954.

(31) Reas, W. H. , Quarterly Progress Report, July - Sept. , 1954, HW-33496, p. 31 . 
per cent TBP-hydrocarbon mixture to be $7.0 \times 10^{-4}$ moles $/ 1,(32)$, and a first order consecutive reaction, it is found that in the absence of light $\mathrm{k}_{1}=1 \times 10^{-5} \mathrm{hr}^{-1}$ ( step two hydrolysis is negligible), and in the light, $\mathrm{k}_{1}=5.0 \times 10^{-3} \mathrm{hr}^{-1}, \mathrm{k}_{2}=2.8 \times 10^{-2} \mathrm{hr}^{-1}$. This calculation for the reaction in the light reveals two very interesting points. The first is that the rate is several hundred times faster than in the dark reaction, and the second is that the second step, the hydrolysis of DBP has changed from a slower step to one which is five times faster than the hydrolysis of TBP. An alternative explanation of the second point is that the aqueous solution was not initially saturated with $T B P$, since a lower initial concentration would raise the $r$ atio of $k_{1}$ to $k_{2}$. If one assumes that $\mathrm{k}_{1}=3 \mathrm{k}_{2}$ or the apparent ratio from data obtained in the absence of uranium, then it is found that $\mathrm{k}_{1}=2 \times 10^{-2} \mathrm{hr}^{-1}$ and that the initial concentration of TBP corresponds to 22 per cent of saturation, a possible but unlikely situation. In any case, the observation of a greatly increased rate of hydrolysis in uranium solutions in the presence of light is still valid.

Swanson ${ }^{(33)}$ working with a similar solution investigated the formation of DBP at $50 \mathrm{C}$. Starting with $0.15 \mathrm{~g} \mathrm{TBP} / 1$ in a solution of $0.05 \mathrm{M}$ nitric acid and $0.25 \mathrm{M}$ uranyl nitrate, a, series of 12 experiments at $48 \mathrm{C}$ with light excluded showed a linear formation of DBP with time. In 70 hours, $2.2 \mathrm{mg} / 1\left(1.05 \times 10^{-5}\right.$ moles/1) were formed. The amount of DBP formed represents only about 2 per cent of the initial TBP present. The data obtained are fitted by $\mathrm{k}_{1}=3.0 \times 10^{-4} \mathrm{hr}^{-1}$. If the activation energy is assumed to be $14 \mathrm{kcal}$, (see Section VI D), then at $25 \mathrm{C} \mathrm{k}_{1}=6 \times 10^{-5}$, which can be compared to $1 \times 10^{-5}$ found from Brite's data. The factor of six here could possibly be explained by assuming that the initial TBP concentration in Brite's experiment was below saturation by that amount.

(32) Burger, L. L., Forsman, R. C., The Solubility of Tributyl Phosphate in Aqueous Solutions, HW-20936, April 2, 1951.

(33) Swanson, J. L., HAPO, unpublished work. 
Data recently reported by Woodfield ${ }^{(34)}$ make possible a further check of the above data. An "RCU" sample containing some entrained TBP was heated at $50 \mathrm{C}$ and the DBP concentration followed for about 50 hours. The data are given in Table III.

\section{T ABLE III}

\section{Formation of DBP in RCU}

$\mathrm{RCU}=0.25 \underline{\mathrm{M}} \mathrm{UO}_{2}\left(\mathrm{NO}_{3}\right)_{2}, 0.05 \underline{\mathrm{M} \mathrm{HNO}}_{3}$ in $\mathrm{H}_{2} \mathrm{O}$

Temperature - $50 \mathrm{C}$

\begin{tabular}{c} 
Time, hrs. \\
\hline 0 \\
8 \\
24 \\
48 \\
54
\end{tabular}

54

\begin{tabular}{cc}
\multicolumn{2}{c}{ DBP Concentration } \\
\hline Parts per $10^{6}$ parts U & $\frac{\text { M } \times 10^{5}}{1.0}$ \\
36 & 1.32 \\
47 & 2.50 \\
89 & 3.64 \\
130 & 2.50 \\
89 &
\end{tabular}

The DBP concentration in two other samples was followed after first removing the excess organic phase. No detectable difference from the first experiment was found. Since the aqueous phase was saturated, the initial TBP concentration should have been about $7.4 \times 10^{-4} \underline{M}^{(32)}$. As in Swanson's work, less than 10 per cent of the dissolved TBP was destroyed during the time involved. * Thus as long as the excess organic phase volume was small enough, i. e., <0.1 per cent, such that the organic phase reaction was not significant, ** then no difference in the DBP formation should be expected in the three samples.

Values of $\mathrm{k}_{1}=9 \times 10^{-4} \mathrm{hr}-1, \mathrm{k}_{2}=4 \times 10^{-4}$ fit the data with an uncertainty of about 20 per cent up to 48 hours. The 54 hour point must be questioned, for if $\mathrm{k}_{1}>\mathrm{k}_{2}$ then the DBP concentration cannot drop as long as $\left[\mathrm{TBP}^{-} \cong\left[\mathrm{TBP}_{\text {initial }}\right.\right.$. This rate is three times higher than that found by Swanson and about 18 times that extrapolated from Brite's data. The initial TBP concentration appears firmly fixed in

(34) Woodfield, F. W. , Progress Report, Chemical Development Unit, Sept. 1954, HW-33297, Sept. 30, 1954 .

* 120 hours are required to destroy 10 per cent of the TBP if $k_{1}=$ $9 \times 10^{-4} \mathrm{hr}^{-1}$.

** See 4-c, p. 32, this section. 
Woodfield's experiment. The experimental control and analytical data are probably much better in Brite's and Swanson's work. One can only conclude that the rate constants for DBP formation and destruction in this solution cannot be fixed at present with any degree of certainty. It is suggested that Swanson's data be accepted at the present time. Typical data are shown in Figure 3.

In nitric acid solutions the agreement is a little better, as can be seen in Table $\mathrm{V}$ where the TBP data are summarized. There is doubt concerning the nitric acid dependence. The data indicate an order somewhat less than one over the concentration range of 1 to 6 M nitric acid.

c. Alkaline Hydrolysis

The alkaline hydrolysis of TBP has been studied only in a two phase system. Kennedy and Grimley ${ }^{(35)}$ observed the rate of hydrolysis of TBP in $1.02 \mathrm{M}$ sodium hydroxide from $30 \mathrm{C}$ to $100 \mathrm{C}$. No difference was found when the organic phase volume was changed, and it was concluded that the reaction occurred only in the aqueous phase. Table IV gives the amount reacted per hour in $100 \mathrm{ml}$ of aqueous phase. The solubility is estimated by the writer, from data given by Burger and Forsman ${ }^{(32)}$ and Kennedy and Grimley, (36) as $0.16 \mathrm{~g} / 1$ at $30 \mathrm{C}$ from pure $\mathrm{TBP}$ and $0.10 \mathrm{~g} / 1$ from 20 per cent TBP. The rather uncertain 10 to 20 per cent decrease in solubility as the temperature is raised with a minimum around $70 \mathrm{C}$ is ignored for lack of precise data. With these data, the rate constants included in Table IV were computed. The data are plotted in Figure 2. An activation energy of about $18 \mathrm{kcal}$ is indicated. The data for 100 per cent TBP give slightly higher rate constants but probably within the error of the estimated solubilities.

(35) Kennedy, J., Grimley, S. S., Radiometric Studies with Phosphorus -32 Labelled Tri-n-butyl Phosphate, AERE-CE-R-1284, Dec. 18, 1953.

(36) Kennedy, J., Grimley, S. S., Radiometric Studies with Phosphorus -32 Labelled Tri-n-butyl Phosphate, Part I, Solubility and Distribution Studies, AERE-CE-R-1283, Dec. 1, 1953. 


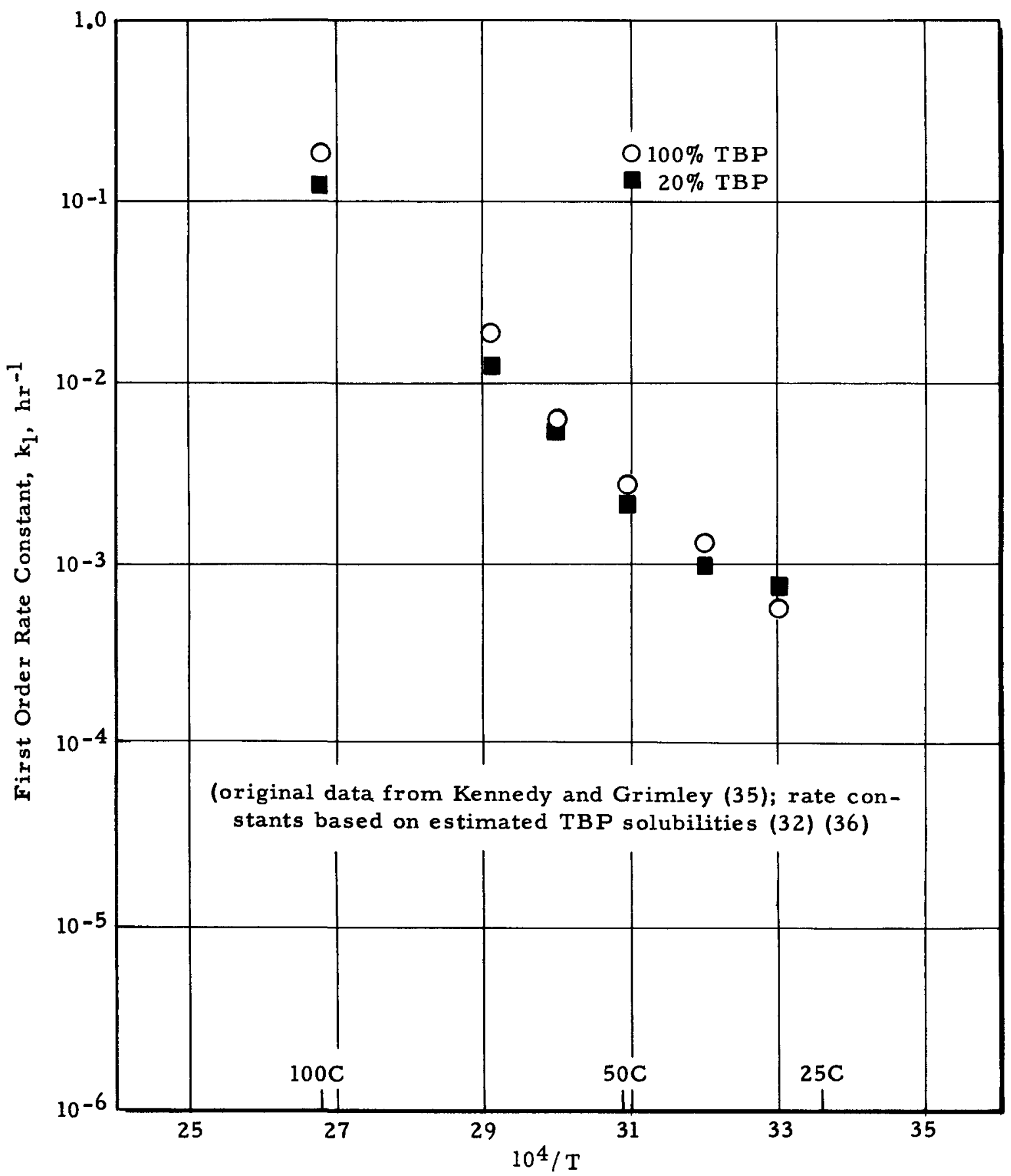

FIGURE 2

HYDROLYSIS OF TBP BY 1 M SODIUM HYDROXIDE 


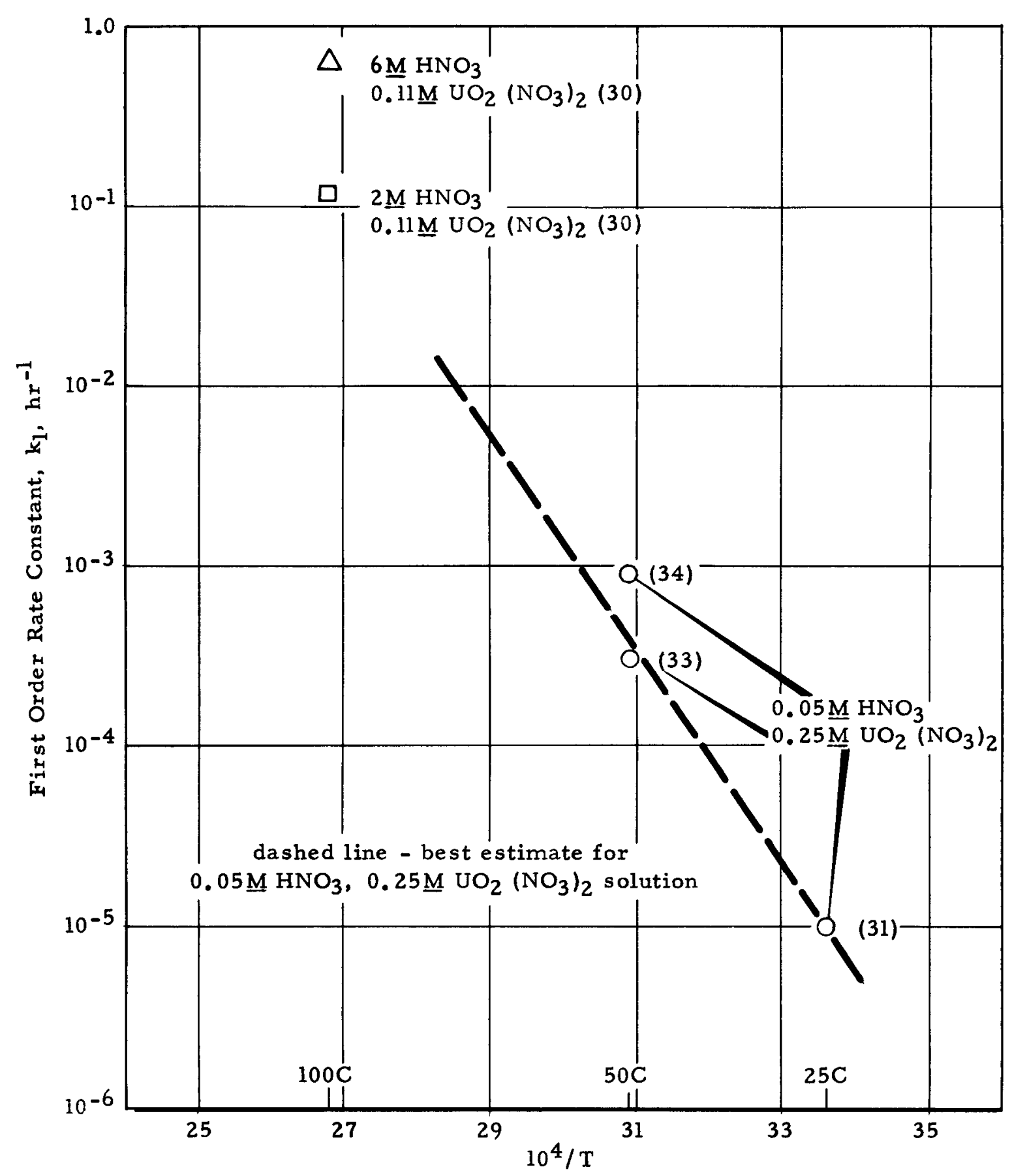

F IGURE 3

AQUEOUS HYDROLYSIS OF TBP (URANYL NITRATE SOLUTIONS) 
Pollack $^{(37)}$ has reported results on the hydrolysis of $200 \mathrm{ml}$ of TBP with $200 \mathrm{ml}$ of 10 per cent sodium hydroxide at the boiling point. In four hours 0.148 moles of alcohol were produced. ${ }^{*}$ Since the solubility of TBP at this high caustic concentration is even more uncertain than for the previous case, and since the experiment was complicated by the fact that the mixture was being continually distilled as the reaction progressed, a rate constant was not estimated. However, the observed rate, $419 \mathrm{~g} / \mathrm{hr}$ TBP reacted per $100 \mathrm{ml}$ of aqueous phase, is over 100 times faster than that observed by Kennedy and Grimley, Table IV.

\section{Summary of Aqueous Phase Data for TBP}

With the aid of the data on other alkyl phosphates reported in Section VI, the aqueous phase hydrolysis reactions of TBP can be summarized in the following manner:

a. Relative Rates of the Hydrolysis Steps

In the stepwise hydrolysis of the trialkyl phosphate esters, the first stage giving dialkyl phosphate is always more rapid than the second and third steps. In nitric acid solutions or uranyl nitrate solutions, the relative rates appear to be about $4: 2: 1$ for the three steps ending in phosphoric acid. This is supported by the data for triethyl phosphate and trimethyl phosphate. In the region of $\mathrm{pH}=2$ to $\mathrm{pH}=10$, the ratio of the rates is unknown. The pronounced effect of $\mathrm{pH}$ on the third step showing a maximum rate at $\mathrm{pH}=4.0$ may be absent with trialkyl esters and may vary appreciably for dialkyl esters. Alkaline hydrolysis is probably more rapid than acid hydrolysis, but the reaction stops at the dialkyl phosphate.

(37) Pollack, H., Investigation of the Chemical and Physical Properties of Tributyl Phosphate, DPST-53-41-11, Aug。 19, 1953.

* Other work has indicated, Section VI-D, that alkaline hydrolysis stops the dialkyl phosphate; thus the alcohol produced is equivalent to the TBP reacted. 
TABLE IV

HYDROLYSIS OF TBP IN $1 \mathrm{M}$ NaOH SOLUTIONS

Source - Kennedy and Grimley

Temp. C

30

40

50

60

70

100
Pure TBP

$\frac{(\mathrm{a})}{8.8 \times 10^{-5}}$
$1.96 \times 10^{-4}$
$4.37 \times 10^{-4}$
$9.59 \times 10^{-4}$
$3.04 \times 10^{-3}$
$2.83 \times 10^{-2}$

$\mathrm{k}_{1} \mathrm{hr} \mathrm{r}^{-1}$

$5.5 \times 10^{-3}$

$1.2 \times 10^{-2}$

$2.7 \times 10^{-2}$

$6.0 \times 10^{-2}$

0.19

1.78
$20 \%$ TBP in Kerosene

\begin{tabular}{cc}
\hline (a) & $\mathrm{k}_{1} \mathrm{hr}$ \\
\hline $7.08 \times 10^{-5}$ & $7.0 \times 10^{-3}$ \\
$9.59 \times 10^{-5}$ & $9.6 \times 10^{-3}$ \\
$2.17 \times 10^{-4}$ & $2.2 \times 10^{-2}$ \\
$5.79 \times 10^{-4}$ & $5.8 \times 10^{-2}$ \\
$1.22 \times 10^{-3}$ & 0.12 \\
$1.20 \times 10^{-2}$ & 1.2
\end{tabular}

(a) grams reacted per $100 \mathrm{ml}$ of solution per hour.

b. Acid Strength

At concentrations between $1 \underline{M}$ and $6 \underline{M}$ nitric acid, the reactions are somewhat less than first order with respect to acid concentration, although there is not sufficient data to indicate whether the order is closer to $1 / 2$ or to 1 . The order probably increases at higher acid concentrations $(\underline{M}>6)$. This is supported by the data of Desjorbet on triethyl phosphate, Table XXI. As the acidity is lowered the rate, at least for the monoesters, passes through a minimum at about $\mathrm{pH}=1$, rises to a maximum at $\mathrm{pH}=3$ to 4 and then drops to an extremely low value at $\mathrm{pH}=8$. The diester might be expected to be $\mathrm{pH}$ sensitive but no data are available.

c. Nature of the Acid

It is reasonably certain that the hydrolysis rates in halogen acids are much higher than in nitric or sulfuric acid. The order for the third step at concentrations of 1 to $5 \underline{\mathrm{M}}$ acid is $\mathrm{HI}>\mathrm{HBr}>$ $\mathrm{HCl}>\mathrm{HNO}_{3} \geqslant \mathrm{H}_{2} \mathrm{SO}_{4} \cdot$ For the first and second hydrolysis steps, there is no direct comparison; however, as will be seen in Section D-4, there is evidence for the same trend. 
d. Uranium and Light

The reactions are accelerated by factors of several hundred if uranium is present and the if systems are exposed to light. Data suggest, but do not prove conclusively, that the rate of DBP destruction is greater than the rate of formation for these conditions.

The hydrolysis rate in $0.25 \mathrm{M} \mathrm{UO}_{2}\left(\mathrm{NO}_{3}\right)_{2}, 0.05 \underline{\mathrm{M}} \mathrm{HNO}_{3}$ in the absence of light is uncertain, but probable values of $\mathrm{k}_{1}$ are $4 \times 10^{-5} \mathrm{hr}^{-1}$ at $25^{\circ}$ and $4 \times 10^{-4} \mathrm{hr}^{-1}$ at $50^{\circ}$, based largely on Swanson's measurements. These data are shown in Figure 3 。

e. The Alkyl Group

The generalization of Kosolapoff $(38)$ that increased radical size increases resistance to hydrolysis is not unequivocably supported. As will be seen later (see Section VI-D) the rule appears to be true in comparing the methyl and ethyl esters. Further, in mixed esters the smaller group is removed preferentially. However, the available data for the ethyl phosphates, propyl phosphates, butyl phosphates and octyl phosphates suggest that there is relatively little difference in stability. Substitution on the alkyl groups leading to greatly different electro-negativities may have much more effect on the stability.

\section{f. Temperature}

In acid solution, the activation energy for the first step in the hydrolysis of TBP is of the order of 12 to $14 \mathrm{kcal}$. This is supported by data on TMP and TEP and also by considerable work on phosphates of biochemical interest (Section VI-D). In strongly alkaline solution, the data of Kennedy and Grimley for TBP hydrolysis give an activation energy of $18 \mathrm{kcal}$. Since the mechanism may be different in different aqueous solutions, one

(38) Kosolapoff, G. M., Organophosphorus Compounds, New York: John Wiley and Sons, (1950), p. 232 .

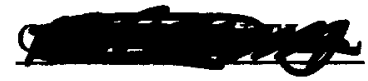


TABLE V

SUMMARIZED RATE CONSTANTS FOR THE AQUEOUS HYDROLYSIS OF TBP

\begin{tabular}{|c|c|c|c|c|c|}
\hline System & $\begin{array}{l}\text { Temp. } \\
\text { C. } \\
\end{array}$ & $\begin{array}{l}\mathrm{k}_{1}{ }^{(1)} \\
\mathrm{hr}^{-1} \\
\end{array}$ & $\begin{array}{l}\mathrm{k}_{2} \\
\mathrm{hr}^{-1} \\
\end{array}$ & $\begin{array}{l}\mathrm{k}_{3} \\
\mathrm{hr}^{-1}\end{array}$ & Reference \\
\hline $\begin{array}{l}8.6 \overline{\mathrm{M} \mathrm{HNO}_{3}} \\
5.4 \mathrm{MNO}_{3} \\
1.04 \underline{\mathrm{M}} \mathrm{HNO}_{3}\end{array}$ & $\begin{array}{l}116 \\
108 \\
101\end{array}$ & $\begin{array}{l}0.32 \\
0.20 \\
0.056\end{array}$ & $\begin{array}{l}-- \\
-- \\
--\end{array}$ & $\begin{array}{l}-- \\
-- \\
--\end{array}$ & $\begin{array}{l}(28) \\
(28) \\
(28)\end{array}$ \\
\hline $\begin{array}{l}6 \mathrm{MNNO} \mathrm{HNO}_{3} \\
0 . \overline{\mathrm{I}} \stackrel{\mathrm{M}}{-} \mathrm{UO}_{2}\left(\mathrm{NO}_{3}\right)_{2}\end{array}$ & 100 & $0.61^{(2)}$ & $0.20^{(2)}$ & $0.14^{(2)}$ & (30) \\
\hline $\begin{array}{l}2 \mathrm{M} \mathrm{HNO} \\
0 . \overline{\mathrm{N}} \underline{\mathrm{M} \mathrm{UO}}{ }_{2}\left(\mathrm{NO}_{3}\right)_{2}\end{array}$ & 100 & $0.113^{(2)}$ & $0.043^{(2)}$ & $0.030^{(2)}$ & (30) \\
\hline $\begin{array}{l}0.2 \mathrm{M} \mathrm{HNO} \\
0.11^{-}-\mathrm{UO}_{2}\left(\mathrm{NO}_{3}\right)_{2}\end{array}$ & 100 & -- & 0.014 & -- & (30) \\
\hline $6 \underline{\mathrm{M}} \mathrm{HNO}_{3}$ & 105 & 0.072 & -- & -- & (27) \\
\hline $3 \underline{\mathrm{M}} \mathrm{HNO}_{3}$ & $\begin{array}{r}105 \\
76\end{array}$ & $\begin{array}{l}0.04 \\
7.5 \times 10^{-3}\end{array}$ & $3.4^{--} \times 10^{-3}$ & $1.6^{--} \times 10^{-3}$ & (27) \\
\hline $5 \underline{\mathrm{M}} \mathrm{HNO}_{3}$ & 75 & 0.014 & -- & -- & (29) \\
\hline $\begin{array}{l}0.05 \mathrm{M} \mathrm{HNO} \\
0.25 \underline{\mathrm{M}} \mathrm{UO}_{2}\left(\mathrm{NO}_{3}\right)_{2}\end{array}$ & 48 & $3.0 \times 10^{-3}$ & -- & -- & (33) \\
\hline$\left\{\begin{array}{l}0.05 \mathrm{M} \mathrm{HNO} \\
0.25 \underline{\mathrm{M}} \mathrm{UO}_{2}\left(\mathrm{NO}_{3}\right)_{2}\end{array}\right.$ & 50 & $9.0 \times 10^{-4}$ & -- & -- & (34) \\
\hline
\end{tabular}



would not necessarily expect a constant activation energy. Typical aqueous phase data are shown in Figures 2 and 3.

4. Two-Phase Systems and the Organic-Phase "Hydrolysis"

Since alkaline hydrolysis occurs primarily in the aqueous phase, for the organic phase only the acid or neutral hydrolysis need be considered. TBP is only slightly soluble in water and the first hydrolysis product DBP is nearly all distributed into the organic phase in the presence of acid. ${ }^{(39)}$ Thus with two-phase mixtures the non-aqueous reactions may be the more significant.

\section{a. Anhydrous Dealkylation}

Reference has been made earlier to the dealkylation reactions in anhydrous systems. The esters of the phosphorus acids undergo carbon-oxygen cleavage with mineral acids, a reaction which is useful in the synthesis of phosphonic and phosphinic acids. Alkyl phosphates with hydrochloric acid yield alkyl halides and the acid esters. Although the kinetics of these reactions have not generally been studied, a typical view of the rates is given by the work of Gerrard, et al. ${ }^{(26)}$ These authors employed hydrochloric acid and hydrobromic acid to dealkylate TBP, triisobutyl phosphate, trisecondary butyl phosphate and triisooctyl phosphate. Hydrogen chloride gas passed into TBP and the solution stored for 12 hours at $17 \mathrm{C}$ yielded 0.43 moles of butyl chloride per mole TBP. However, a period of three weeks was required, a portion of the time at elevated temperatures, to obtain 2.75 moles of butyl chloride.

b. Water-Saturated TBP, Neutral Hydrolysis

Dawson and Lowe ${ }^{(11)}$ have investigated the hydrolysis of pure TBP and TBP diluted with kerosene after saturating with water.

(39) Burger, L. L. , Partitition of Dibutyl Phosphate, HW-33682, Nov. 8, 1954. 
The DBP was estimated by equilibrating with distilled water and measuring the $\mathrm{pH}$ of the aqueous phase. Any MBP or phosphoric acid present would be reported as DBP. For the undiluted TBP hydrate they found 0.001 per cent in ten days at room temperature and 0.01 per cent in 24 hours at $100 \mathrm{C}$. These correspond to rate constants of $2 \times 10^{-7} \mathrm{hr}^{-1}$ and $2 \mathrm{x}$ $10^{-5} \mathrm{hr}^{-1 *}$, respectively, and an activation energy of $14 \mathrm{kcal}$.

Dilution of the TBP with four volumes of kerosene reduced the rate to 0.0005 per cent in ten days at room temperature. In another experiment a sample of the TBP hydrate was heated at 95 to $100 \mathrm{C}$ for 110 hours and titrated with $0.1 \mathrm{M}$ sodium hydroxide. MBP was indicated by the $\mathrm{pH}$ curve and phosphoric acid was found gravimetrically. The results given in the text of the report are 0.011 per cent DBP, 0.003 per cent MBP and 0.012 phosphoric acid*. These numbers give a rate constant for TBP decomposition of $\mathrm{k}_{1}=1.1 \times 10^{-5} \mathrm{hr}^{-1}$. However, if one uses the data directly from the titration plot and assumes that the " $5 \mathrm{ml}$ of TBP hydrate" represents pure TBP and not the 20 per cent dilution, one obtains $k_{1}=2.2 \times 10^{-5} \mathrm{hr}^{-1}$, in good agreement with the $\mathrm{pH}$ method given above.

c. Hydrolysis with Acid Present

Since the successive hydrolysis products of any of the alkyl phosphates become more and more organic insoluble, and it is difficult to follow the reactions without the separation of a second phase, most of the work on the organic phase reactions of TBP has been in two phase systems.

Wagner"s work included several two phase systems, some of which were discussed earlier in this section. The reaction

*Dawson and Lowe report percentages referred to 20 per cent TBP in kerosene. Hence, a factor of five must be included to convert to $\mathrm{k}$ values as given in the present report. 
between TBP and 3 M nitric acid in equal volumes was observed at $70 \mathrm{C}$ and $105 \mathrm{C}$. No MBP was found. At $76 \mathrm{C}$ he reported one per cent hydrolysis in 30 days and at $105 \mathrm{C}$ a 2.2 per cent hydrolysis in 13 days. In both cases an induction period of several days was observed. His conclusion that the initial step, $\mathrm{TBP} \longrightarrow \mathrm{DBP}$, was rate determining is not sound since the DBP concentration was never determined. There are insufficient data to permit calculation of individual rate constants. His other experiments with $3 \mathrm{M}$ nitric acid at 1:1 phase ratios and 200:1 aqueous to organic ratios and with 6 M nitric acid were mentioned in Part 2 of this section. Recalculation of $\mathrm{k}_{1}$ for the organic phase for these experiments places $\mathrm{k}_{1}$ in the region $3.4 \times 10^{-5} \mathrm{hr}^{-1}\left(\operatorname{mol~} \mathrm{HNO}_{3}\right)^{-1}$ to $2.5 \times 10^{-4} \mathrm{hr}^{-1}$ $\left(\mathrm{mol} \mathrm{HNO}_{3}\right)^{-1}$ at $105 \mathrm{C}$ with a probable value of about $1 \times 10^{-4}$. It is virtually impossible to evaluate rate constants from the data at $76 \mathrm{C}$ since only phosphoric acid was determined.

Among the best data available are those of Kennedy and Grimley. (35) Phosphorus -32 was used to permit determination of the products radiometrically. The hydrolysis of TBP as a function of temperature, acid present, phase volume ratio and dilution of the TBP was studied. The reaction times and phase volume ratios were chosen such that the TBP concentration could be considered constant and the aqueous concentration of acid was not changed by extraction. Experiments with different volume ratios indicated that the degradation was independent of the volume of the aqueous phase. The contribution of the aqueous phase was therefore negligible, and the fraction decomposed per unit time can be considered a rate constant for the organic phase hydrolysis. Their data are reproduced in full in Table VI. First order rate constants may be taken as these values divided by 100 . 
TABLE VI

TBP HYDROLYSIS AS A FUNCTION OF TEMPERATURE

Kerosene Diluent

Per Cent TBP Reacted per Hour

Kennedy and Grimley( $(35)$

\begin{tabular}{|c|c|c|c|c|c|}
\hline \multirow[b]{2}{*}{ Temp. C. } & \multirow{2}{*}{$\frac{1 \mathrm{M} \mathrm{HCl}}{\text { Pure TBP }}$} & \multicolumn{2}{|c|}{$1 \mathrm{M} \mathrm{HNO}_{3}$} & \multicolumn{2}{|c|}{$5 \mathrm{M} \mathrm{HNO}_{3}$} \\
\hline & & Pure TBP & $20 \%$ TBP & Pure TBP & $20 \%$ TBP \\
\hline 21 & -- & -- & 0.583 & 2. 54 & 1.0 \\
\hline 30 & 3.92 & 1.42 & 1.08 & 7.08 & 1. 71 \\
\hline 40 & 6.79 & 3.33 & 2.63 & -- & -- \\
\hline 50 & 20.5 & 12.1 & 4.79 & 55.0 & 84.1 \\
\hline 60 & 86.2 & 27.1 & 12.5 & 192.0 & 32.3 \\
\hline 70 & 347.0 & 105.0 & 22.9 & 421.0 & -- \\
\hline 100 & 950.0 & -- & -- & -- & -- \\
\hline
\end{tabular}

In addition, there is reported at room temperature, $(\sim 20 \mathrm{C})$ in contact with $8 \mathrm{M}$ nitric acid a rate for pure TBP of $4.1 \times 10^{-4}$ per cent $\mathrm{hr}^{-1}$ and for 20 per cent TBP, $1.3 \times 10^{-4}$ per cent hr $\mathrm{hr}^{-1}$. These workers state that at constant acidity at $30 \mathrm{C}$ the difference in reaction rate, is roughly proportional to the product of $\mathrm{TBP}$ concentration (or solvent acidity) and the activity coefficient $(\sim 2.6)$ of TBP in 20 per cent TBP*.

The actual acid concentration in the organic phase varies with both the TBP concentration and the aqueous acid concentration. Table VII lists these concentrations (HAPO data). If the above rate constants at $30 \mathrm{C}$ are divided by the actual nitric acid concentration in the organic phase, the data listed in the last column are obtained. It is seen that in the case of $1 \underline{M}$ nitric acid, the activity coefficient correction is reasonable and in the

*The activity coefficient is based on the solubility of TBP in water from 20 per cent TBP referred to the solubility of pure TBP. 
case of $5 \underline{M}$ acid, it is not. An interesting result from this latter comparison is the much higher rate, per unit acid concentration, in the case of hydrochloric acid. This supports the aqueous phase data of Baldwin and Higgins. (29) Activation energies calculated from the data have the following values: $100 \%$ TBP - HCl, $29 \mathrm{kcal} ; 100 \%$ TBP-HNO 3 , $21 \mathrm{kcal} ; 20 \%$ TBP-HNO 3 , $14 \mathrm{kcal}$. From the smoothed curves, estimated rate constants in 20 per cent TBP at $25 \mathrm{C}$ for contact with $1 \underline{\mathrm{M}}$, $5 \mathrm{M}$ and $8 \mathrm{M}$ aqueous solutions of nitric acid can be given as $7 . \overline{2} \times 10^{-7}, 1.2 \times 10^{-6}$, and $2 \times 10^{-6} \mathrm{hr}{ }^{-1 *}$, respectively. At $50 \mathrm{C}$ corresponding values would be $5.6 \times 10^{-6}, 1.0 \times 10^{-5}$ and $1.4 \times 10^{-5} \mathrm{hr}^{-1}$.

\section{TABLE VII}

ORGANIC RATE CONSTANTS BASED ON UNIT ACID CONCENTRATION Temperature, $30 \mathrm{C}$

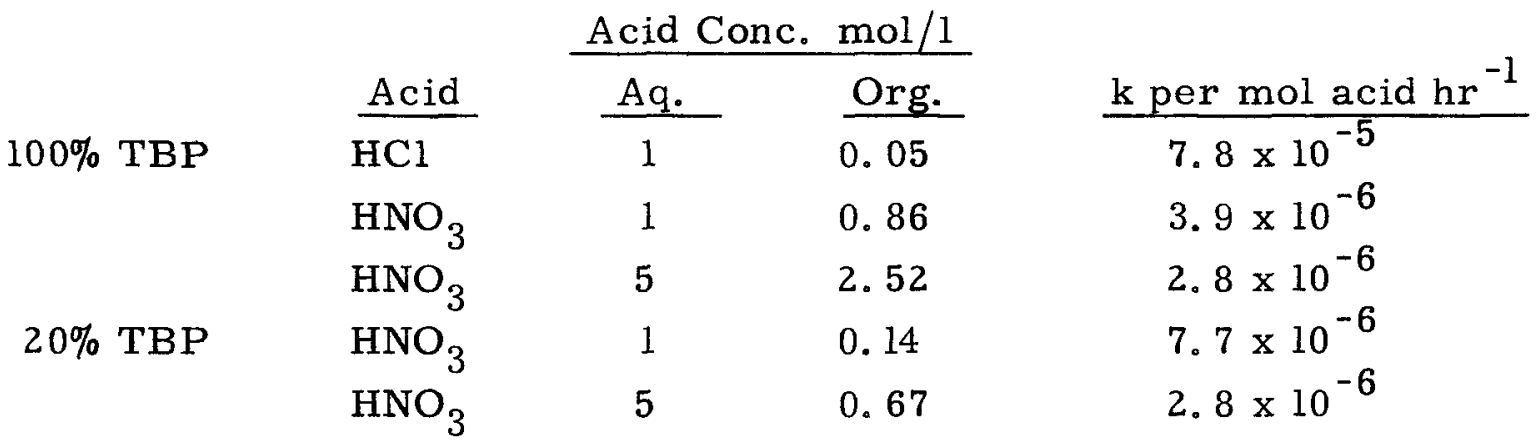

From Table V or Figure 1 , the best value of $\mathrm{k}_{1}$ for the aqueous phase hydrolysis in $5 \underline{\mathrm{M}}$ nitric acid is $7 \times 10^{-4} \mathrm{hr}^{-1}$ at $30 \mathrm{C}$. Thus it is seen that the ratio of the rate constants for the aqueous phase and for the organic phase (pure TBP) is

* The value for $8 \mathrm{M}$ is uncertain since the exact temperature was not specified. A temperature change of $5 \mathrm{C}$ is equivalent to a change of about 30 per cent in $\mathrm{k}$. 
about 100, which when multiplied by the ratio of TBP concentrations in the two phases $\frac{4.1 \times 10^{-4}}{3.50}$, gives $1.2 \times 10^{-2}$. Thus for pure TBP in contact with an equal volume of aqueous $5 \underline{M}$ $\mathrm{HNO}_{3}, 99$ per cent of the reaction occurs in the organic phase. With $1 \underline{M}$ acid about 97 per cent would occur in the organic phase. In acid hydrolysis in two phase systems, then, the aqueous phase reaction can generally be ignored as stated by Lanham and Reilly and by Kennedy and Grimley, and makes possible evaluation of the miscellaneous rate measurements reported for two phase systems. The reaction of equal volumes of TBP and $8 \mathrm{M} \mathrm{HNO}_{3}$, reported by Baldwin and Higgins, gave 0.28 per cent decomposed in 29 days. This is equivalent to $\mathrm{k}_{1}=3.9 \times 10^{-6} \mathrm{hr}^{-1}$. Kennedy's and Grimley's "room temperature value of $4.1 \times 10^{-6} \mathrm{hr}^{-1}$, also with $8 \mathrm{M} \mathrm{HNO}_{3}$, is an excellent check.

Lanham and Reilly ${ }^{(28)}$ stored an equal volume of 30 per cent TBP in Amsco 123-15 with 7.2 M nitric acid at 25 C. Two separate experiments gave $\mathrm{k}_{1}=2.2 \times 10^{-5} \mathrm{hr}^{-1}$ and $1.6 \times 10^{-5}$ $\mathrm{hr}^{-1}$. At $70 \mathrm{C}, 30$ per cent TBP in contact with 2.5 volumes of $6.0 \mathrm{M}$ nitric acid gave 0.4 per cent decomposition in 3 hours or $\mathrm{k}_{1}=1.3 \times 10^{-3} \mathrm{hr}^{-1}$. No measurement was made of the subsequent hydrolysis steps but a study of the plutonium nitrate distribution in the systems led to the conclusion that the major component of the hydrolysis products was DBP. An activation energy of the order of $19 \mathrm{kcal}$ was indicated for the over-all TBP destruction. As can be seen in Figure 4, their rates are higher by a factor of about ten than the bulk of the data from other sources indicates. Feber ${ }^{(40)}$ has reported the rate of formation of DBP in equal volumes of 100 per cent TBP and

(40) Feber, R. C. , et al. , Report for the Chemistry and Chemical Engineering Section, Aug. -Sept.-Oct., 1953, KAPL-1002, p. 73, January 11, 1954. 


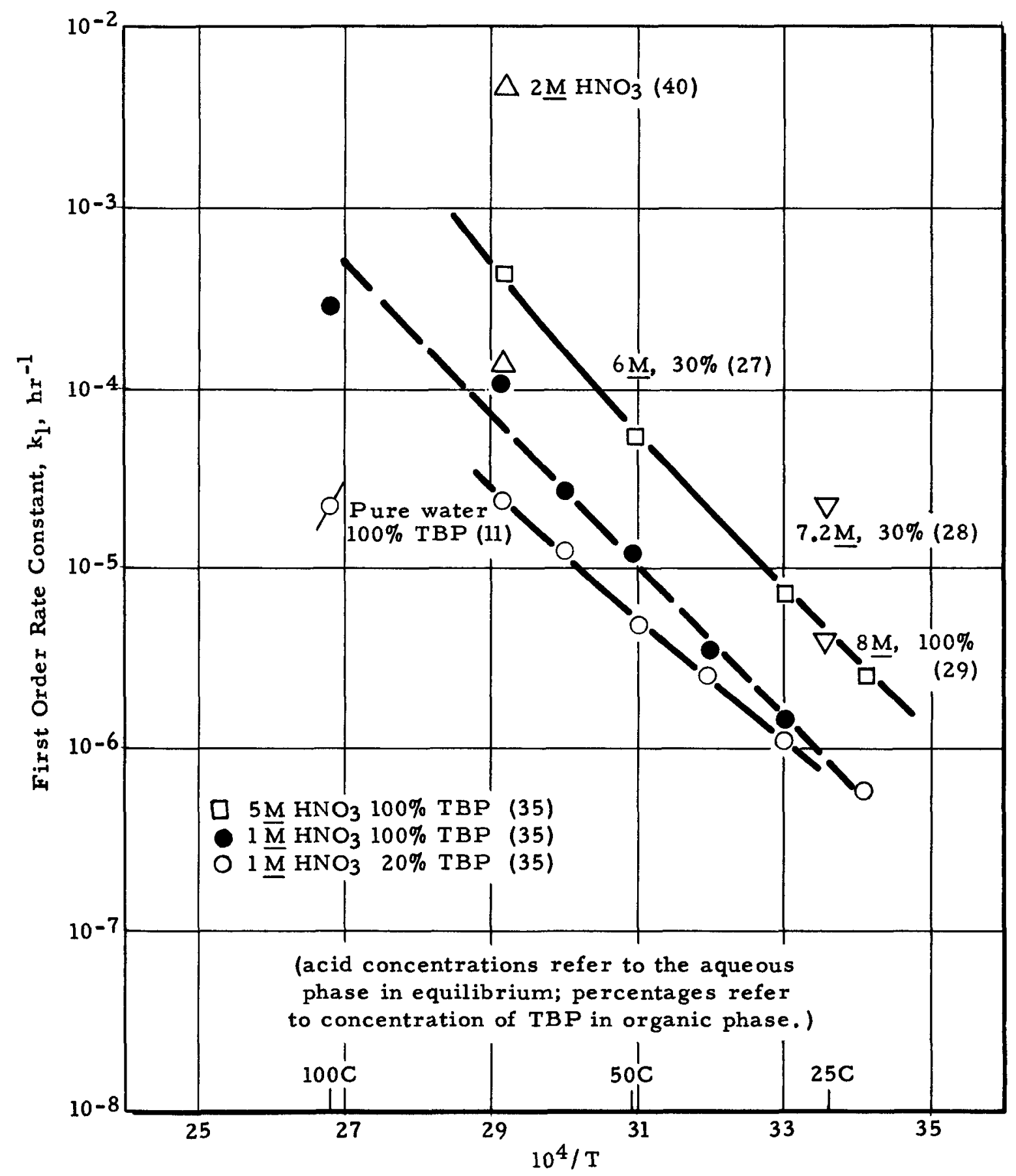

F IGURE 4

ORGANIC PHASE HYDROLYSIS OF TBP 


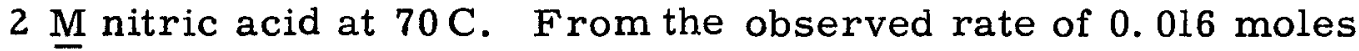
DBP per liter of TBP per hour, a rate constant $\mathrm{k}_{1}=4.6 \times 10^{-3}$ $\mathrm{hr}^{-1}$ is calculated. This value is about ten times higher than that found by Kennedy and Grimley.

d. Hydrolysis with Acid and Uranium Present

The effect of uranium in the organic phase on the reaction rates is uncertain. Rodden ${ }^{(41)}$ reports total DBP, MBP and phosphoric acid formed in a two phase reaction at $80 \mathrm{C}$. Four experiments were performed. (l) The first system was 30 per cent TBP in kerosene containing $10 \mathrm{~g} / 1$ nitric acid and $100 \mathrm{~g} / 1$ uranium as uranyl nitrate, with 10 . volume per cent of water added. After the mixture was agitated for a week, 3.48 per cent of the TBP was hydrolyzed. (2) The same solution but without uranium gave 1.09 per cent. (3) A similar experiment to the first, with a one-half volume of $6 \underline{\mathrm{M}}$ nitric acid in place of the water, gave 1.58 per cent, and (4) without uranium present, gave 2.48 per cent. Rate constants for these reactions are $2 \times 10^{-4}, 6 \times 10^{-5}, 1 \times 10^{-4}$, and $1.5 \times 10^{-4} \mathrm{hr}^{-1}$, respectively. Results from solutions without uranium present are in reasonable agreement with the data of Kennedy and Grimley. No mention is made as to whether light was exluded during the reactions. Assuming that light was not involved, one might deduce from the above experiments that adding uranium to the organic phase increases the rate by a factor of three, since the nitric acid in the organic phase is not greatly different (experiments 1 and 2). Experiments 3 and 4 are not necessarily in disagreement, since distribution calculations show that Experiment 4 has a higher nitric acid concentration in the

(41) Rodden, C. J. , Progress Report for Period Ending June 30, 1951, NYO-2021, December 21, 1951. 
organic phase, $0.8 \underline{M}$ as compared to $0.1 \underline{M}$ in Experiment 3. Recent data of Swanson ${ }^{(42)}$ can be compared here. Aqueous phases having the initial compositions indicated in Table VIII were equilibrated with an equal volume of 30 per cent TBP in Shell Spray Base and agitated in the absence of light at $50 \mathrm{C}$.

TABLE VIII

FORMATION OF DIBUTYL PHOSPHATE IN TBP

Equal Volumes of Aqueous Phase and 30 Per cent TBP-Spray Base Source - Swanson ${ }^{(42)} \quad$ Temperature - $50 \mathrm{C}$

\begin{tabular}{|c|c|c|c|c|c|}
\hline Initial Aq. Solution & \multicolumn{2}{|c|}{$\frac{\text { Final Org. Phase }}{\text { Composition } *}$} & $\begin{array}{c}\text { Reaction } \\
\text { Time- } \\
\text { Hrs. } \\
\end{array}$ & $\frac{\mathrm{DBP}}{\mathrm{g} / 1}$ & $\frac{\frac{\text { Rate Constant }}{\text { Org. Phase }}}{\text { hr-1 }}$ \\
\hline $0.092 \underline{\mathrm{M}} \mathrm{UO}_{2}\left(\mathrm{NO}_{3}\right)_{2}$ & 0.08 & 0.75 & 26 & 0.11 & \\
\hline $5.2 \mathrm{M} \mathrm{HNO}_{3}$ & & & 54 & 0.21 & $2.7 \times 10^{-5}$ \\
\hline $0.02 \underline{\mathrm{M} \mathrm{NaNO}} \mathrm{N}_{2}$ & & & 145 & 0.44 & \\
\hline & & & 118 & 0.50 & \\
\hline $0.57 \underline{\mathrm{MUO}} \mathrm{UO}_{2}\left(\mathrm{NO}_{3}\right)_{2}$ & 0.4 & 0.23 & 122 & 0.17 & $9 \times 10^{-6}$ \\
\hline $\begin{array}{l}3.5 \underline{\mathrm{M}} \mathrm{HNO}_{3} \\
0.05 \underline{\mathrm{M} \mathrm{NaNO}} \mathrm{NaN}_{2}\end{array}$ & & & 197 & 0.44 & \\
\hline
\end{tabular}

(42) Swanson, J. L., HAPO, unpublished work.

(43) Line, L. E. , Jr., Progress Report, Purex Lab. Dev., Feb. -April, 1952, ORNL-1343, October 9, 1952. 
As the buildup of DBP in this experiment appears to be linear with time, the second step was ignored and the rate constant $\mathrm{k}_{1}$ was calculated directly from the data. The amount of TBP destroyed is negligible. For the first solution $k_{1}=2.7 \times 10^{-5}$ $\mathrm{hr}^{-1}$. The data for the second experiment are more uncertain. An average of two points gives $\mathrm{k}_{1}=9 \times 10^{-6} \mathrm{hr}^{-1}$.

As a comparison, for the case with no uranium present, the data of Kennedy and Grimley for $0.8 \mathrm{M} \mathrm{HNO}_{3}$ in 20 per cent TBP gave $\mathrm{k}_{1}=1.5 \times 10^{-5} \mathrm{hr}^{-1}$ at $50 \mathrm{C}$. Their value, using 100 per cent TBP, was $3.5 \times 10^{-5} \mathrm{hr}^{-1}$ at $50 \mathrm{C}$.

Brite ${ }^{(44)}$ measured the DBP formation rate in systems composed of equal volumes of $121 / 2$ per cent TBP in Shell Spray Base and aqueous phases containing uranyl nitrate and nitric acid. The solutions were kept in brown bottles at $50 \mathrm{C}$ and mixed once each day. The initial aqueous phases were as indicated in Table IX. The first order rate constants listed in the last column were calculated by the writer assuming that only the organic phase reaction is significant and that the second step in the hydrolysis is negligible. The latter assumption is valid for $\mathrm{k}_{2} \mathrm{t}<<\mathrm{l}$ or $\mathrm{t}<$ 500 hours. The data are also included in Table XI along with estimated organic phase compositions. These rate constants are much higher than those of previous work. Further, the DBP concentration appears to be rising in the aqueous phase rapidly and at concentration levels much higher than one can reconcile with the distribution coefficient $\mathrm{E}_{\mathrm{a}}^{\mathrm{O}}$ of $\mathrm{DBP}$, which is $>100$ for these systems.

Table $\mathrm{X}$ summarizes the organic phase hydrolysis data for TBP. Some of the better data are reproduced in Figure 4.

(44) Brite, D. W. , Observation of Hydrolysis Rate of Butyl Phosphates, HW-Undocumented, February 2, 1954 . 
TABLE IX

DBP FORMA TION IN TBP DILUENT MIXTURES

Organic phase $-121 / 2$ per cent TBP in Shell "Spray Base"

Temperature, $50 \mathrm{C}$

Aqueous Phase

before Equilibrium

2. $0 \mathrm{M} \mathrm{UO}_{2}\left(\mathrm{NO}_{3}\right)_{2} 6.0 \mathrm{M} \mathrm{HNO}$

$\begin{array}{lll}\text { " } & 2.0 & \\ & 0.2 & \end{array}$

18

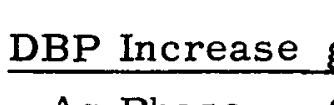
Aq Phase

0.028

0.0064

0.0005

0.017

0.00036

0.0005
Source - Brite $(44)$

$0.11 \underline{\mathrm{M} \mathrm{UO}}{ }_{2}\left(\mathrm{NO}_{3}\right)_{2} 6.0 \underline{\mathrm{M}} \mathrm{HNO}_{3}$
2. 0 "
0.211
$1 "$
$" 1$
0.

*Estimate

5. Summary of Organic-Phase Hydrolys is of TBP

\section{a. Acid Dependence}

Alkaline hydrolysis does not occur in the organic phase. Neutral hydrolysis increases as the amount of water in the organic phase increases, and for pure-water-saturated TBP at $25 \mathrm{C}$, the first order rate constant is $2 \times 10^{-7} \mathrm{hr}^{-1}$, and at $100 \mathrm{C}$ is $2 \times 10^{-5} \mathrm{hr}^{-1}$, indicating an activation energy of about $14 \mathrm{kcal}$. The rate constants for acid-catalyzed hydrolysis are much higher. At $30 \mathrm{C}$, the rate constant for pure TBP in contact with 5 M nitric acid is $7.1 \times 10^{-6} \mathrm{hr}^{-1}$ per mole of acid in solution. The acid dependence is approximately first order, although the dependence is very uncertain at low acid concentrations (less than $1 \underline{M}$ ). Halogen acids are more effective than nitric acid or sulfuric acid. 
TABLE X

SUMMARIZED RATE CONSTANTS FOR THE ORGANIC PHASE HYDROLYSIS OF TBP

Organic Phase Composition

Aqueous Phase

Composition

\begin{tabular}{|c|c|c|c|}
\hline \multicolumn{3}{|c|}{ during Reaction } & Temp \\
\hline$\%$ TBP & $\underline{\mathrm{M}} \mathrm{HNO}_{3}$ & Other & ${ }^{\circ} \mathrm{C}$ \\
\hline 100 & -- & - & 100 \\
\hline
\end{tabular}

First Order Rate

$\mathrm{H}_{2} \mathrm{O}$

100

0.86

-- 70

50

30

21

$1 \underline{\mathrm{M} \mathrm{HNO}} 3$

20

0.14

$--$

70

50

30

21

$5 \mathrm{M} \mathrm{HNO}_{3}$

100

2.5

-- 70

50

30

21

$5 \underline{\mathrm{M}} \mathrm{HNO}_{3}$

20

0.67

$--$

50

30

21

$2 \mathrm{M} \mathrm{HNO}_{3} \quad 100$

0.4 (a)

70

$8 \mathrm{M} \mathrm{HNO}_{3} \quad 100$

3 (a)

- $\quad$ "room"

Constant

$\frac{\mathrm{k}_{1}}{2.2 \times 10^{-5}}$

$2.8 \times 10^{-4}$

2. $7 \times 10^{-5}$

3. $3 \times 10^{-6}$

$1.4 \times 10^{-6}$

Ref.

$8 \mathrm{M} \mathrm{HNO}_{3} \quad 100$

3 (a)

2. $3 \times 10^{-5}$

4. $8 \times 10^{-6}$

1. $1 \times 10^{-6}$

5. $8 \times 10^{-7}$

7. $2 \mathrm{M} \mathrm{HNO}_{3} \quad 30$

1. 2 (a) -- 25

$4.2 \times 10_{-5}^{-4}$

$5.5 \times 10^{-5}$

$7.1 \times 10^{-6}$

6. 0 M $\mathrm{HNO}_{3} \quad 30$

1.1 (a) -- 70

2. $5 \times 10^{-6}$

$8.4 \times 10^{-6}$

1. $7 \times 10^{-6}$

1. $0 \times 10^{-6}$

$4.6 \times 10^{-3}$

$4.1 \times 10^{-6}$

$3.9 \times 10^{-6}$

3-6 $\mathrm{M} \mathrm{HNO}_{3} \quad 100$

$\begin{array}{ccc}1.5-3.5 & -- & 105 \\ & - & 105\end{array}$

$1.9 \times 10^{-5}$

$1.3 \times 10^{-3}$

(a) Estimated.

(b) Computed as $\mathrm{k}$ per mol of acid assuming first order acid dependence.

(c) Recalculated by the author. 
TABLE X (contd.)

\begin{tabular}{|c|c|c|c|c|c|c|}
\hline \multirow{3}{*}{$\frac{\text { Aqueous Phase }}{\text { Composition }}$} & \multicolumn{4}{|c|}{ Organic Phase Composition } & \multirow{3}{*}{$\frac{\text { First Order Rate }}{\frac{\text { Constant }}{\mathrm{k}_{1}}}$} & \multirow[b]{3}{*}{ Ref. } \\
\hline & \multicolumn{3}{|c|}{ during Reaction } & \multirow{2}{*}{$\frac{\text { Temp. }}{{ }^{\circ} \mathrm{C} .}$} & & \\
\hline & $\%$ TBP & $\underline{\mathrm{M} \mathrm{HNO}} 3$ & Other & & & \\
\hline $\mathrm{H}_{2} \mathrm{O} 10 \%$ by vol. & 30 & 0.16 & $0.42 \mathrm{M}$ & 80 & $2 \times 10^{-4}$ & (41) \\
\hline & 30 & 0.16 & $\left.0 . \sigma^{(2)} 3\right)$ & 280 & $6 \times 10^{-5}$ & $(41)$ \\
\hline $6 \mathrm{M} \mathrm{HNO}_{3} 50 \%$ & 30 & 0.16 & $0.42 \mathrm{M}$ & 80 & $1.0 \times 10^{-4}$ & (41) \\
\hline & 30 & 0.16 & $\begin{array}{l}\mathrm{UO}_{2}\left(\mathrm{NO}_{3}\right) \\
0.0\end{array}$ & 280 & $1.5 \times 10^{-4}$ & (41) \\
\hline $\begin{array}{l}0.092 \underline{\mathrm{M} \mathrm{U}} \\
5.2 \underline{\mathrm{M}} \mathrm{HNO}_{3}\end{array}$ & 30 & 0.75 & $\begin{array}{l}0.08 \mathrm{M} \\
\mathrm{UO}_{2}(\overline{\mathrm{NO}} 3) \\
+ \text { some H. }\end{array}$ & $\mathrm{HNO}_{2}^{50}$ & $2.7 \times 10^{-5}$ & $(42)$ \\
\hline $\begin{array}{l}0.57 \underline{\mathrm{M} \mathrm{U}} \\
3.5 \underline{\mathrm{M} \mathrm{HNO}} 3\end{array}$ & 30 & 0.23 & $\begin{array}{l}0.4 \mathrm{M} \\
\mathrm{UO}_{2}\left(\overline{\mathrm{NO}_{3}}\right)\end{array}$ & )$_{2}^{50}$ & $9 \times 10^{-6}$ & $(42)$ \\
\hline$\underset{\mathrm{HNO}_{3}}{2.0 \mathrm{M}}, 6.0 \underline{\mathrm{M}}$ & 12.5 & $0.1(a)$ & 0.23 (a) & 50 & $5.5 \times 10^{-4}$ & $(44)$ \\
\hline $\begin{array}{l}2.0 \mathrm{M} \mathrm{U}, 2.0 \mathrm{M} \\
\mathrm{HNO}_{3}\end{array}$ & 12.5 & $0.1(a)$ & $0.23(\mathrm{a})$ & 50 & $1.4 \times 10^{-4}$ & $(44)$ \\
\hline $\begin{array}{l}\text { 2. } 0 \mathrm{MN} \mathrm{U}, 0.2 \mathrm{M} \\
\mathrm{HNO}_{3}\end{array}$ & 12. 5 & 0.1 (a) & $0.23(a)$ & 50 & $5.5 \times 10^{-5}$ & $(44)$ \\
\hline$\underset{\mathrm{HNO}_{3}}{0.11 \mathrm{M} U}, 6 \underline{\mathrm{M}}$ & 12.5 & 0.2 (a) & $0.1(a)$ & 50 & $5.5 \times 10^{-4}$ & $(44)$ \\
\hline$\underset{\mathrm{HNO}_{3}}{0.11 \mathrm{M}}, 2 \underline{\mathrm{M}}$ & 12.5 & $0.1(a)$ & $0.1(a)$ & 50 & $5.5 \times 10^{-4}$ & $(44)$ \\
\hline$\underset{\mathrm{HNO}_{3}}{0.11 \mathrm{M} U, 0.2 \underline{\mathrm{M}}}$ & 12.5 & 0.1 (a) & $0.02(a)$ & 50 & $5.1 \times 10^{-5}$ & $(44)$ \\
\hline $1 \underline{\mathrm{M} \mathrm{HCl}}$ & 100 & -- & $\begin{array}{l}0.05 \\
\mathrm{HCl}\end{array}$ & 70 & $3.5 \times 10^{-4}$ & (35) \\
\hline
\end{tabular}

(a) Estimated.

(c) Recalculated by the author. 
b. Uranium

The effect of uranium is uncertain. Data exist which indicate both increased and decreased rates. It is probable that at a given nitric acid concentration, the addition of uranium in the absence of light does not change the rate by more than a factor of two. In the presence of light, uranium increases the hydrolysis rate.

c. Temperature

Activation energies reported range from about 14 kcal for watersaturated TBP to $29 \mathrm{kcal}$ for TBP containing hydrochloric acid. For nitric acid-catalyzed hydrolysis the activation energy is $21 \mathrm{kcal}$ and $14 \mathrm{kcal}$, respectively, for 100 per cent TBP and 20 per cent TBP in kerosene.

6. Other Products of Hydrolysis

The emphasis in Section III-E has been on the formation of DBP, MBP and phosphoric acid. In aqueous systems, the other product of reaction is butyl alcohol. The fate of the alcohol may be removal by distillation, by solvent partition in extraction cycles, or by chemical reaction. The last may involve either formation of butyl nitrate or oxidation. At high nitrate concentrations butyl nitrate may form as a primary reaction product, and evidence for its direct formation from the acid "hydrolysis" of TBP at temperatures above $100 \mathrm{C}$ was presented by Nichols。(45) Subsequent work indicated that butyl nitrate was the major reaction product of TBP and nitric acid solutions at these temperatures. Nichols also observed that small amounts of nitric oxide were formed in the reaction, indicating that some oxidation was occurring. Butyl nitrate will, of course, hydrolyze to butyl alcohol. No data have been reported for the acid hydrolysis of butyl nitrate. The alkaline hydrolysis is extremely slow. (46)

(45) Nichols, G. M. , Siddall, T. N., III, Savannah River Laboratory TNX Semi-Works, Bi-Weekly Report, April 28, 1953, May 14, 1953.

(46) Baker, J. W. , Easty, D. M., J. Chem. Soc., 1952, 1193. 
If oxidation of the alcohol occurs, then aldehydes and carboxylic acids would be expected. Brite ${ }^{(47)}$ has considered the possibility that butyraldehyde may form through the reaction of nitric acid and the hydrolysis products of TBP. In subsequent treatment of the solvent with alkaline wash solutions, he suggests that polymers could form by aldol condensation. It is important to remember that diluents commonly used with TBP may be a more likely source of these products.

7. Hydrolysis of TBP Derivatives

The reactions of TBP derivatives are significant both because of their possible presence in solutions of practical interest and because their behavior may aid in the interpretation of TBP reactions. Inorganic pyrophosphates hydrolyze in water at a rate which is first order with respect to both pyrophosphate concentration and hydrogen ion concentration. $(48)$

The condensed phosphates may be considered as the anhydrides of dibutyl (or monobutyl) phosphoric acid. Thus, their hydrolysis yields DBP and/or MBP. Tetrabutyl pyrophosphate, TBPP, is the simplest of these structures and its behavior is probably typical.

Toy ${ }^{(49)}$ has studied the tetraalkyl pyrophosphates as a class. The methyl, ethyl, propyl, isopropyl and butyl compounds were prepared and their hydrolysis in water studied. The resistance to hydrolysis increased with the size of the alkyl group; the isopropyl derivative

(47) Bushey, A. H. , Quarterly Progress Report, Chem. Unit, Jan. -Mar. 1954, HW-31630, p. 63, May l, 1954.

(48) Sidgwick, N. V. , Chemical Elements and Their Compounds, Oxford: Clarendon Press, London (1950) p. 744.

(49) Toy, A. D. F., J. Am. Chem. Soc. 70, 3882 (1948). 
was exceptionally stable. In a stirred two phase system with water, the TBPP hydrolyzed to DBP at the rates shown in Table XI. A plot of the logarithm of the unreacted pyrophosphate against time shows an increasing rate with time, possibly due to the increasing acidity and/or increasing solubility.

\section{T ABLE XI}

HYDROLYSIS OF TETRABUTYL PYROPHOSPHATE IN CONTACT WITH WATER Temperature, $25 \mathrm{C}$

Time (Days)

5

10

15

20

25

30

\section{Per cent Reacted} 4

20

40

62

79

91

The initial rate corresponds to a half-life of about 30 days, $\mathrm{k} \sim 10^{-3} \mathrm{hr}-1$, while after 90 per cent had reacted the half-life was eight days. By comparison to the rates of hydrolysis of the lower pyrophosphates, it is probable that the reaction occurred largely in the aqueous phase. Lack of solubility data precludes calculation of individual rate constants. It may be noted, however, that the overall rate is roughly 100 times as fast as the hydrolysis of TBP. The alkaline hydrolysis of TBPP has not been studied but must be slow, since it is possible to synthesize the pyrophosphates from dialkyl chlorophosphates using sodium bicarbonate to remove the hydrochloric acid formed. This may not be true for all pyrophosphates, for Ketelaar and Blacksma ${ }^{(50)}$ found a rapid hydrolysis of tetraethyl pyrophosphate in sodium hydroxide solutions. Their first order rate constant at $25 \mathrm{C}$ was $0.093 \mathrm{hr}^{-1}$.

(50) Ketelaar, J. H. A., Blacksma, A. H., Rec. Trav. Chim., 67665 (1948). 
8. Mechanism of Hydrolysis

The organic phosphates that have been studied in most detail are those of biochemical interest, which often have reactive substituents. These functional groups may become directly involved in the hydrolysis reactions, or change the electron density about the phosphate nucleus such that these esters no longer serve to elucidate a general mechanism. The most comprehensive study of ester hydrolysis concerns the carboxylic acid esters, a study pioneered by Lowry ${ }^{(51)}$ and co-workers. Ingold has contributed generously to this field and has recently summarized this work. ${ }^{(24)}$ Here again the mechanism involving a $\mathrm{R}-\mathrm{C}(0)-0$-configuration is not necessarily representative of a $R-0-P(0)-0$-group, but enough similarities exist to permit classification in a like manner. Thus, we can consider alkaline, neutral or acid hydrolsis. Secondly, the reaction may be classified according to whether alkyl-oxygen fission or phosphorus-oxygen fission occurs, and finally whether the controlling step is monomolecular or bimolecular.

A consistent mechanism (or mechanisms) should account for the following observations of alkyl phosphate hydrolysis:

(1) Alkaline hydrolysis occurring only in the aqueous phase and stopping at the first hydrolysis product; e.g. , TBP terminates in DBP.

(2) A much greater rate of acid hydrolysis in aqueous solutions than in organic solutions.

(3) A dependence on acid concentration which is variable and slightly less than first order.

(4) The differing effect of various acids: $\mathrm{HI}>\mathrm{HCI}>\mathrm{HNO}_{3} \geqslant \mathrm{H}_{2} \mathrm{SO}_{4}$.

(51) See for example Waters, W. A. , Physical Aspects of Organic Chemistry, New York: Van Nostrand (1950) p. $327 \mathrm{ff}$. 
In addition, one would hope to be able to predict:

(1) The relative rates of the three steps in the hydrolysis of TBP.

(2) The effect of complexing the TBP by other components.

(3) Catalysts that would hinder or accelerate one or more of the steps.

a. Alkaline Hydrolysis

Two possible mechanisms of alkaline hydrolysis of TBP are:

$$
\begin{aligned}
& \mathrm{HO}^{-}+\mathrm{Bu}-\mathrm{O}-\mathrm{P}(\mathrm{O})(\mathrm{OBu}) \underset{2}{\longrightarrow} \mathrm{BuOH}+(\mathrm{BuO})_{2} \mathrm{P}(\mathrm{O}) \mathrm{O}^{-} \\
& \text {or } \\
& \mathrm{HO}^{-}+(\mathrm{BuO})_{3} \mathrm{P} \mathrm{O} \rightarrow \mathrm{BuO}^{-}+(\mathrm{BuO})_{2} \mathrm{P}(\mathrm{O}) \mathrm{OH} \\
& \left.\begin{array}{l}
(\mathrm{BuO})_{2} \mathrm{P}(\mathrm{O}) \mathrm{OH}+\mathrm{HO}^{-} \longrightarrow \mathrm{H}_{2} \mathrm{O}+(\mathrm{BuO})_{2} \\
\mathrm{BuO}^{-}+\mathrm{H}_{2} \mathrm{O} \longrightarrow \mathrm{BuOH}+\mathrm{HO}^{-}
\end{array}\right\}
\end{aligned}
$$

Mechanism (1) would be favored by very electropositive alkyl groups, and esters of strong acids. Neither condition fits TBP very closely.

Reaction (1) leads to an alkyl-oxygen split while reaction (2) leads to a phosphorus-oxygen split. Blumenthal and Herbert $(25)$ using tracer oxygen observed that triethyl phosphate gave 100 per cent phosphorus oxygen cleavage with sodium hydroxide in aqueous solution, in support of mechanism (2). There is also considerable confirming evidence. Nucleophilic attack by the $\mathrm{OH}^{-}$group requires an electroposition center, and the first step probably involves the attachment of the $\mathrm{OH}^{-}$group to the phosphorus atom. Thus, it is not surprising that the reaction slows greatly after the first hydrolysis step, for in alkaline solution the hydrolysis product will exist as the ion which is further strengthened by resonance. 
<smiles>[R]OP(=O)([O-])O[R]</smiles><smiles>[R]O[PH]([O-])([O-])O[R]</smiles>

The phosphorus atom is less positive than in the parent compound TBP where the structure<smiles>[R]O[P+]([O-])(O[R])O[R]</smiles>

has an appreciable contribution.

However, a number of cases exist where the hydrolysis does not stop after the first alkyl group is removed. For example, diisooctyl phosphate according to Gerrard and his co-workers, $(26)$ hydrolyzed rapidly with $1 \mathrm{M}$ potassium hydroxide at the reflux temperature. Koshland ${ }^{(5 \overline{2})}$ found that acetyl phosphate hydrolyzed at an increasingly rapid rate as the $\mathrm{OH}^{-}$concentration was increased above a pH of 10 . In the latter case, the acetyl carbon may be involved.

The alkaline hydrolysis is an ionic one and requires a media having a high dielectric constant; e. g. , aqueous solutions. The mechanism postulated is bimolecular, which is consistent with the first order dependence on both $\mathrm{OH}^{-}$and phosphate. (This second order kinetic law has been demonstrated for many phosphates although not specifically for TBP.)

(52) Koshland, D. E., Jr., J. Am. Chem. Soc. 74, 2286 (1952). 
The increased stability toward alkaline hydrolysis of the phosphothioates, $(\mathrm{RO})_{3} \mathrm{PS}$, over the phosphates $(53)$ is consistent with the mechanism since in the former case the phosphorus is less positive.

Recently Amber and his co-workers ${ }^{(54)}$ have examined with the aid of tracer oxygen the alkaline hydrolysis of esters of a variety of inorganic acids. In this rather complete study the electropositive nature of the alkyl group, the acid strength and the oxidation state of the central atom were all varied. The majority of the esters retained the alkyl-oxygen bond on hydrolysis. Of the esters which hydrolyzed by alkyl-oxygen fission, all contained a tertiary carbon-oxygen bond. Several other esters of strong acids including $\mathbf{n}$-butyl nitrate hydrolyzed partially by this mechanism. Esters of phosphoric acid were not included in the study.

b. Acid Hydrolysis

The case for acid hydrolysis is more complex as reactions in both aqueous and organic media must be considered. By analogy to the carboxylic acid esters, a possible mechanism would be:<smiles>[R]OP(=O)(O[R])O[PH2+]PP(=O)(O[R])O[R]</smiles>

This product would then add a hydroxyl group (extremely unlikely due to the low $\mathrm{OH}^{-}$concentration) or a water molecule to the central atom and the resulting unstable configuration would

(53) Ketelaar, J. H. A., et al., Rec. Trav. Chim. 71, 1253 (1952).

(54) Amber, M., et al., J. Chem. Soc., 1954, 3603. 
cleave at the P-O bond, giving ROH. However, for TBP a more plausible reaction would involve adding a proton to the electronegative phosphoryl oxygen giving the structure<smiles>[R]O[R7]([R])(O[R])O[P+]([R])(O[R])O[R]</smiles>

followed by<smiles>[R]O[R7](O[R])(O[2H])OP(=O)(O[R])O[R]</smiles>

This mechanism was suggested by Blumenthal and Herbert to account for the 70 per cent cleavage of the alkyl oxygen bond which was observed for triethyl phosphate. In concentrated acids the second step could involve the acid anion instead of water, resulting in the ester $\mathrm{RX}$ in place of $\mathrm{ROH}$. Since 30 per cent $\mathrm{P}-\mathrm{O}$ bond fission was found by Blumenthal and Herbert, reactions (4a) and (4b) do not occur exclusively. Reaction (4b) could be replaced by nucleophilic attack by a water molecule. Since the acids, nitric, hydrochloric and hydrobromic which have roughly equivalent degrees of ionization show different catalytic effects, one may reason that the acid anion is involved in the second step. 
In non-aqueous media the proton addition must be replaced by molecular addition of the acid; e. g. ,

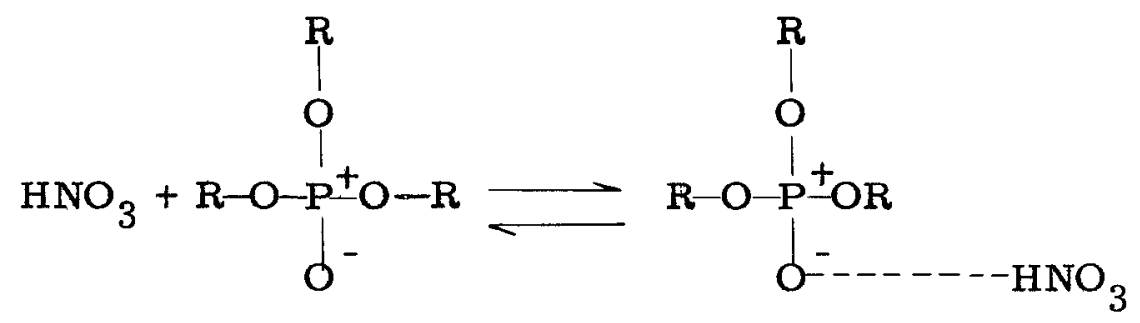

The second step would involve (a) splitting off of an alkyl nitrate molecule internally or a biomolecular reaction involving either (b) a water molecule or (c) another acid molecule. The second step depends on the relative rate constants $k_{a}, k_{b}$ or $k_{c}$ ' respectively, and on the relative concentrations of ester, water and acid. Reaction (5) above reaches equilibrium rapidly. Thus (a), (b) or (c) is probably rate controlling. Both butyl alcohol and butyl nitrate have been found in hydrolysis reactions with nitric acid but the latter only in significant quantities at high temperatures, $>100 \mathrm{C}$, and high acid concentrations. $(45)(55)$ Since butyl nitrate is moderately stable toward hydrolysis, $(46)(54)$ the evidence for water-saturated solutions points to reaction (4b), although there is no reason to assume that only one reaction path is followed in such complex mixtures as watersaturated TBP-kerosene containing both uranyl nitrate and nitric acid. As the concentration of uranyl nitrate or acid is increased the water content is diminished, and at saturation (with salt) the solvent is nearly anhydrous. Under this condition, mechanism (b) would become unimportant. The fact that there is competition between the water and acid in the TBP solution and both are required for (4b) may explain the variable

(55) Nichols, G. M. , Siddall, T. H., Savannah River Lab., TNX SemiWorks Bi-Weekly Reports, May 14, 1953, June 23, 1953. 
and less than first order dependence on nitric acid.

The much lower extraction of hydrochloric acid than nitric acid by TBP was noted in connection with the work of Kennedy and Grimley. ${ }^{(35)}$ Yet in view of the rapid hydrolysis with hydrochloric acid a strong complex must exist to be consistent with the postulated mechanism. One must conclude then that it is not the lack of complex strength that prevents hydrochloric acid extraction but rather the solubility characteristics of the complex and the strong complexing of the chloride ions in the aqueous phase. In acid solutions the successive hydrolysis products of TBP are molecular DBP, MBP and finally phosphoric acid. Replacing a butyl group by hydrogen should make the phosphoryl oxygen less basic, although internal hydrogen bonds may complicate this. Thus the trend would be toward a slower reaction as alkyl groups are removed due both to this inductive effect and to the statistical effect; i. e., fewer groups available in the molecule.

c. Neutral Hydrolysis

Neutral hydrolysis can cnly be considered as an independent case over the small range in $\mathrm{pH}$ where the reaction velocities involving either acid or hydroxyl ion are so slow, due to low concentration, that the direct addition of $\mathrm{H}_{2} \mathrm{O}$ to the ester becomes a competitive first step. The very interesting work of Desjorbet on ethyl phosphates ${ }^{(56)}$ and of Koshland ${ }^{(51)}$ on acetyl phosphate (mentioned in Section VI-d) on the effect of $\mathrm{pH}$ on the hydrolysis can be considered an acid hydrolysis study and the rates can be related to the concentrations of the differently charged ester anions present. A transition from an alkaline to an acid hydrolysis mechanism must occur in

(56) Desjorbet, A., Bull. Chem. Soc., 1947, 809. 
this region. With acetyl phosphate independent work by Bentley (57) indicated that the $\mathrm{P}-\mathrm{O}$ bond splits at a $\mathrm{pH}$ of 4 to 6 . This suggests that the acetyl carbon atom is involved in the hydrolysis of this compound.

It is clear that much work must be done before definite mechanism assignments can be made for TBP hydrolysis under the varied conditions of interest. In particular, studies in the organic phase and on the aqueous phase separately should be made so that the effect of acid and water as well as of inert diluent could be studied independently. It is surprising that the formation of a complex as strong as the one formed with uranyl nitrate has shown such little effect on the hydrolysis rates and casts doubt on the above mechanism.

Knowledge of the activation energies of these reactions would also be helpful and are noticeably lacking in most hydrolysis studies. Ketelaar's studies of the $\mathrm{p}$-nitrophenyl phosphates are an exception, as is the work on TBP of Kennedy and Grimley. A curious observation of the latter workers is that the activation energy for hydrolysis of TBP in $1 \mathrm{M}$ sodium hydroxide (approximately $18 \mathrm{kcal}$ ) was about the same as for nitric acid hydrolysis in the organic phase where a completely different mechanism is involved. Yet when the acid hydrolysis of 20 per cent TBP in kerosene was studied, an activation energy of only $14 \mathrm{kcal}$ was found.

E. Radiolysis

No attempt will be made to survey this field here. A study of TBP decomposition by $\boldsymbol{\gamma}$-radiation has recently been made and will soon be published. ${ }^{(58)}$ In addition to hydrogen and small amounts of

(57) Bentley, R. J., Am. Chem. Soc. 71, 2765 (1949).

(58) McClanahan, E. D. , Burger, L. L. , Radiation Stability of Tributylphosphate-Diluent Systems, (to be published). 
hydrocarbons, butyl alcohol, dibutyl ether, and acid phosphates are formed from TBP. The principal product is DBP. Thus, the net result of radiation damage is the same as that from the only important chemical degradation reaction. The DBP produced at a $\gamma$-dosage of $10^{4}, 10^{6}$, and $10^{8} \mathrm{r}$, respectively, has been found to be $0.016 \mathrm{~g} / 1,0.32 \mathrm{~g} / 1,32 \mathrm{~g} / 1$ from pure TBP and $0.0058 \mathrm{~g} / 1,0.099$ $\mathrm{g} / 1$ and $12.2 \mathrm{~g} / 1$ from 30 per cent TBP in an isoparaffin hydrocarbon. At high levels, $>10^{7} \mathrm{r}$, there is also produced a small amount of unknown material which complexes uranium very strongly. By comparison to chemical damage, it can be seen that $10^{4} \mathrm{r}$ is roughly equivalent to contact with $5 \underline{\mathrm{M}}$ nitric acid for 20 hours at $25 \mathrm{C}$.

\section{PROCESS SIGNIFICANCE}

In metal processing by solvent extraction, the difficulties introduced by the chemical reactions of TBP are those associated mainly with the formation of DBP and MBP. These may be present as impurities in the fresh solvent or be produced by hydrolytic reactions. Although DBP and MBP are not volatile and, therefore, are removed by distillation, the preparation and purification of TBP could conceivably leave small amounts of partially esterified phosphorus oxychloride or condensation products, such as dibutyl pyrophosphate or tetrabutyl pyrophosphate (see Section VI). These compounds hydrolyze at a rate several hundred times faster than TBP itself, and hence offer one possible path for the introduction DBP and MBP into TBP. The possibility of formation of metal complexes with the pyrophosphates should not be overlooked in considering TBP as an extractant.

Even if TBP which has had adequate purification is assumed to be obtainable, the problem of hydrolys is of TBP itself remains. This is a problem which one must live with and it is worthwhile to summarize again the rates of hydrolysis: 
HW -40910

\section{A. Water-saturated TBP}

The rate constant of $2 \times 10^{-7} \mathrm{hr}^{-1}$ at $25 \mathrm{C}$ corresponds to a rate of formation of DBP of about $1.4 \times 10^{-4} \mathrm{~g} / 1 / \mathrm{hr}$. Thus a concentration of $0.1 \mathrm{~g} / 1$ would be reached in about 700 hours. At $100 \mathrm{C}$, only 7 hours would be required. For a solution of 30 per cent TBP in an inert diluent, one calculates that the $0.1 \mathrm{~g} / 1$ level would be reached in 2100 hours or 90 days at $25 \mathrm{C}$. However, Dawson and Lowe found a rate lower by about a factor of two if the TBP were diluted with kerosene. Presumably this reflects the lower water to $T B P$ ratio of the diluted TBP, that is, the water content of 30 per cent TBP is much less than 20 per cent of that of pure TBP.

The hydrolysis rates of DBP to MBP and of MBP to phosphoric acid in these solutions are unknown, although it is certain that DBP is formed faster than it is destroyed.

B. TBP in Contact with Nitric Acid-Uranyl Nitrate Solutions

In this system the reaction in the organic phase is the important one. A solution of 30 per cent TBP in a hydrocarbon diluent in contact with $1 \mathrm{M}$ nitric acid will produce about $1.5 \times 10^{-4} \mathrm{~g} \mathrm{DBP} / 1 / \mathrm{hr}$ at $25 \mathrm{C}$ and $1.2 \times 10^{-3} \mathrm{~g} / 1 / \mathrm{hr}$ at $50 \mathrm{C}$. With $5 \mathrm{M}$ nitric acid the rates are about twice as high.

The effect of uranium on the rate of formation of DBP is uncertain. Although data exist which indicate rates 20 times higher for the same nitric acid concentration, it is probable that in the absence of light an increase by a factor of two or less is more likely. If a factor of two is assumed for the uranium effect, then 30 per cent TBP in uranium-containing systems with $5 \mathrm{M}$ nitric acid present might produce DBP at the rate of $5 \times 10^{-3} \mathrm{~g} / 1 / \mathrm{hr}$ at $50 \mathrm{C}$. Increasing the temperature to $70 \mathrm{C}$ would add another factor of four giving $2 \times 10^{-2} \mathrm{~g} / \mathrm{l} / \mathrm{hr}$. It must be emphasized that the latter values are really guesses rather than calculations. 
C. Aqueous Acid Solutions

A separated aqueous phase will contain dissolved TBP in an amount varying inversely as the ionic strength of the solution. A solution of $0.25 \mathrm{M} \mathrm{UO}_{2}\left(\mathrm{NO}_{3}\right)_{2}, 0.05 \mathrm{M} \mathrm{HNO}_{3}$ which has been contacted with 20 per cent TBP will contain $7 \times 10^{-4} \mathrm{~mol}$ of TBP per liter. The first order rate constant for TBP hydrolysis in this solution is about $1 \times 10^{-5} \mathrm{hr}^{-1}$ at $25 \mathrm{C}$ and $3 \times 10^{-4} \mathrm{hr}^{-1}$ at $50 \mathrm{C}$ with an uncertainty factor of about three. The second step, hydrolysis of DBP in aqueous solutions, is probably one-half to one-third as fast. At $50 \mathrm{C}$ then, DBP would initially build up at a rate of $4 \times 10^{-5} \mathrm{~g} / 1 / \mathrm{hr}$ in the above solution, reaching a maximum of about $0.1 \mathrm{~g} / 1$ in one month.

D. Alkaline Solutions

Alkaline hydrolysis is of much less concern, for the reaction occurs only in the aqueous phase. One liter of aqueous $1 \mathrm{M}$ sodium hydroxide in contact with 20 per cent TBP will produce DBP at the rate of $7 \times 10^{-4} \mathrm{~g} / \mathrm{hr}$ at $30 \mathrm{C}$ or $2 \times 10^{-3} \mathrm{~g} / \mathrm{hr}$ at $50 \mathrm{C}$. An important difference in alkaline hydrolysis is that the objectionable reaction products remain in the aqueous phase. The alkaline hydrolysis of DBP and of MBP is extremely slow.

\section{SUGGESTED STUDIES}

The organic phosphorus compounds offer an exciting field for mechanism studies in the field of theoretical organic chemistry. Particularly challenging are the rates of hydrolysis, or dealkylation, in non-aqueous media where little work has been done.

From a practical point of view, this may be the most important area also. For example, the important reactions, as far as mass contribution of degradation products is concerned, have been seen to occur in the organic phase. Yet there is no information on the rate of reactions of the 
first or second hydrolysis products, DBP and MBP, in organic solutions. The major uncertainty in the acid hydrolysis of TBP itself is at low acid concentration, < 0.1 M.

Whether or not uranium affects the hydrolysis rates, as the postulated mechanism would predict, is also uncertain. Swanson's work (Table VIII) indicated a rate higher by a factor of about two than Kennedy and Grimley found for organic phase reactions. The latter experiments (Tables VI, VII) were done in the absence of uranium.

Aqueous phase data also suggest a slightly higher rate. $(30)(31)(33)$ It is suggestive that molybdate ion has a marked catalytic effect on the hydrolysis rate of many acid phosphates. $(59)(60)$ For the same reason, the apparent strong complexing of nitrous acid by TBP would lead one to question the effect of reducing agents in nitric acid systems on the hydrolysis of TBP. The aqueous phase data are more complete, but even here the rate constants in solutions of process interest are not known to better than \pm 50 per cent. The ratio of $k_{2}$ to $k_{3}$ is particulary uncertain.

Finally, the writer feels that some consideration should be given to an elucidation of the mechanism of the hydrolytic reactions of TBP, DBP, and MBP in both phases. There is a definite possibility of controlling the initial destruction of TBP, or increasing the rates of hydrolysis of DBP and/or MBP through catalytic action, and a better understanding of the reaction steps would aid materially in predicting the nature of the required catalyst.

The inadequacy of the information on hydrolysis rates is due in a large part to the difficult analytical problem of determining small concentrations of the different acid esters in the presence of each other and in the presence of large amounts of nitric acid. More extensive use of tracer

(59) Lutwak, L., Sachs, T., J. Biol. Chem. 200, 565 (1953).

(60) Weil-Malherbe, H., Green, R. H. , Biochem. J. 49, 286 (1951). 
phosphorus will be of some aid. For separation of the acid esters, the ionexchange studies of Baldwin and Higgins $(20)(61)$ and the addition products formed with S-benzylthiourea are possible approaches. The latter compound has been used for the characterization of acid phosphates by Lipkin ${ }^{(62)}$ and by Kennedy and Grimley. (63)

Process experience has demonstrated that TBP has adequate chemical stability for use as a solvent in uranium or plutonium separations. This is substantiated by the rate constants for hydrolysis at $25 \mathrm{C}$ listed in this review. However, the use of TBP in acid solution at temperatures higher than $50 \mathrm{C}$ may become marginal insofar as buildup of hydrolysis products is concerned.

The physical properties of TBP, particularly the extraction coefficients for metals, are close to optimum for large scale operation. These factors combined with its availability will assure its continued use for some time to come. It seems reasonable, therefore, that a little more fundamental information on its hydrolytic reactions could be justified. The chemistry of some of the condensation products of TBP also warrants further examination.

\section{APPENDIX}

A. Physical Properties

A summary of pertinent physical properties of TBP is given in Tables XII-XV. The data reported were selected on the basis of apparent purity of the TBP used, judged by density and refractive index and, where it was possible to evaluate, the degree of care employed in the experimental work. Many of the variations in data reported are probably due to small amounts of water which, for example, lower the refractive index and raise the density and

(61) Hill, O. F., Trip Report, Solvent Extraction Studies at ORNL and KAPL HW-19572, Nov. 27, 1950.

(62) Lipkin, D. , The Isolation and Identification of Alkylated Phosphoric Acids, AECD-2234, August 23, 1948.

(63) Kennedy, J., Grimley, S. S., AERE CE/R-968. 
TABLE XII

PHYSICAL PROPERTIES OF TBP

\begin{tabular}{|c|c|c|c|}
\hline Property & Value & Temp ${ }^{\circ} \mathrm{C}$ & Reference \\
\hline Density & $\begin{array}{l}0.9727 \\
0.9730 \\
0.9596\end{array}$ & $\begin{array}{l}25 \\
25 \\
40\end{array}$ & $\begin{array}{l}(64) \\
(72) \\
(64)\end{array}$ \\
\hline Viscosity & 33.2 millipoises & 25 & $(72)$ \\
\hline Boiling Point & $289 \mathrm{C}$ & -- & See Table XIII \\
\hline$\Delta \mathrm{H}$ V ap. & $14.68 \mathrm{kcal} / \mathrm{mole}$ & -- & See Table XIII \\
\hline Melting Point & $-80 \mathrm{C}$ approx. & -- & \\
\hline Solubility & $0.4 \mathrm{~g} / 1$ in $\mathrm{H}_{2} \mathrm{O}$ & 25 & See Table XIV \\
\hline Refractive Index & $\mathrm{n}_{\mathrm{D}}=1.4224$ & 25 & (64) \\
\hline & $\mathrm{n}_{\mathrm{D}}=1.42256$ & 25 & $(73)$ \\
\hline & $\mathrm{n}_{\mathrm{D}}=1.4223$ & 25 & $(75)$ \\
\hline & $\mathrm{n}_{\mathrm{D}}=1.42496$ & 20 & $(65)$ \\
\hline & $\mathrm{n}_{\mathrm{C}}=1.4206$ & 25 & $(64)$ \\
\hline & $\mathrm{n}_{\mathrm{F}}=1.4274$ & 25 & $(64)$ \\
\hline Dielectric Constant & $8.05 \pm 05$ & 25 & $(75)$ \\
\hline Surface Tension & $\begin{array}{l}27.79 \text { dyne/ } \\
28.15 \text { " }\end{array}$ & $\begin{array}{l}20 \\
16.6\end{array}$ & $\begin{array}{l}(65) \\
(65)\end{array}$ \\
\hline $\begin{array}{l}\text { Interfacial Tension } \\
\text { Against } \mathrm{H}_{2} \mathrm{O} \\
\text { Against } 5 \underline{\mathrm{M}} \mathrm{HNO}_{3}\end{array}$ & $\begin{array}{ll}7.4 & \text { dyne } / \mathrm{cm}_{11} \\
8.7 & 11\end{array}$ & $\begin{array}{l}25 \\
25\end{array}$ & $\begin{array}{l}(74) \\
(74)\end{array}$ \\
\hline
\end{tabular}

TABLE XIII

\begin{tabular}{ccc}
\multicolumn{2}{c}{ VAPOR PRESSURE OF TBP } & \\
Temp. & ${ }^{\circ} \mathrm{C}$ & Pressure, $\mathrm{mm} \mathrm{Hg}$ \\
289 & $\frac{760}{227}$ & 150 \\
211 & 100 \\
196 & 50 \\
150 & 10
\end{tabular}

$\log \mathrm{P} \mathrm{mm}=8.5861-\frac{3206.5}{\mathrm{~T}}$ $\Delta \mathrm{H}_{\mathrm{v}}=14680 \mathrm{cal}$. 
TABLE XIV

SOLUBILITY OF TBP IN AQUEOUS SOLUTIONS AT $25 \mathrm{C}^{*}$

(References in parenthesis)*

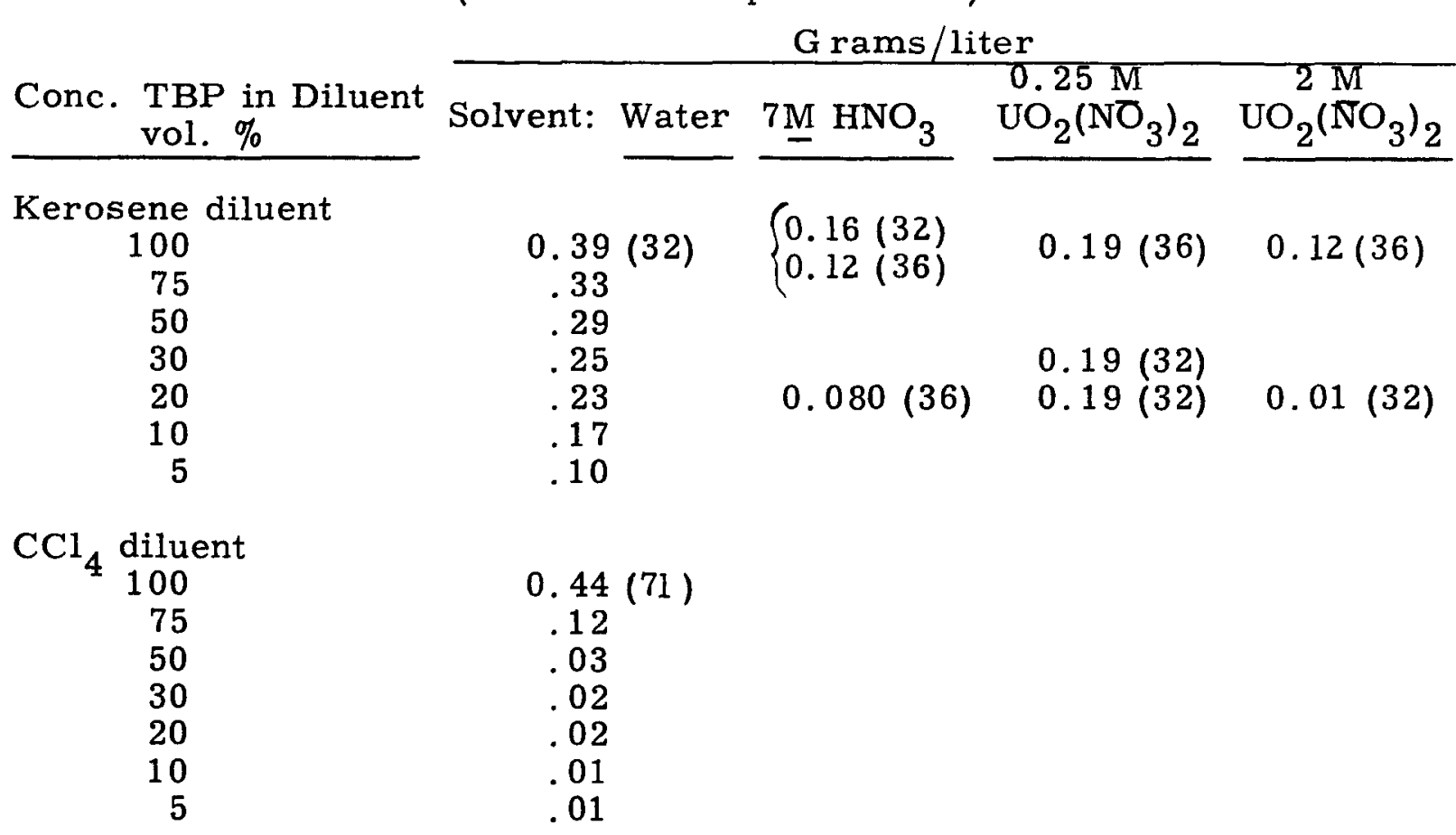

* Data of Kennedy and Grimley (36) are at 17-19 C.

TABLE XV

SOLUBILITY OF WATER IN TBP AT $25 \mathrm{C}$

Vol. \% TBP

Water Content $\mathrm{g} / 1$

in Diluent

$\underline{\text { Kerosene Diluent }}{ }^{(32)} \quad \mathrm{CCl}_{4}$ Diluent $^{(71)}$

100

75

63. 7

37. 1

19. 2

5. 8

25

2. 4

0.54

28. 7

11. 7

15

0.06

3. 7

1. 65

0.1

0

$--$ 
viscosity. Other impurities are butyl alcohol and a variety of phosphorus compounds discussed in Sections III-D-7 and VI-B.

Of some interest in chemical reactions of TBP are the vapor pressure and water solubility. Vapor pressure data have been reported by many workers, $(2)(64-70)$ but only that of Evans ${ }^{(64)}$ appears to represent more than an incidental boiling point measurement. All of the data except those of Lehmann and Flory, Furby and Ashworth and the one-mm point of Wagner are in fair agreement with those of Evans.

Solubilities reported by Kennedy and Grimley ${ }^{(36)}$ are in substantial agreement with those of Burger and Forsman ${ }^{(32)}$ and Baldwin and Higgins ${ }^{(29)}$ and cover a wider selection of aqueous solutions. Craig ${ }^{(70)}$ found much higher solubilities in aqueous solutions. The effect of different diluents on solubility in water was reported by Kennedy and Grimley and studied in more detail by Johnson and Dillon. (71)

(64) Evans, D. P., et al. "The Lower Trialkyl Orthosphosphates, Part I, J. Chem. Soc., 1930, 1310 .

(65) Vogel, A. I., Cowan, D. M. , J. Chem. Soc., 1943, 16.

(66) Noller, C. R., Dutton, G. R. J. Am. Chem. Soc. 55, 424 (1933).

(67) Furby, E. , Ashworth, G。 J., Estimation of Uranium in TBP Solutions, AERE-C/R-617, Dec. 1950.

(68) Wagner, R. M. , Slansky, C. M. , Evaporation of Process Streams in the Tributyl Phosphate Process for Uranium Recovery, HW-15172, Nov. 21, 1949, p. 8.

(69) Lehman, Flory, Durans, et al. (See Beilstein I, 2nd Suppl. p. 397).

(70) Craig, J., Quarterly Report for Period Ending Dec.31, 1951, NYO-2024, p. 17.

(71) Johnson, W. F., Dillon, R. L. , Physical Properties of Tributyl Phosphate-Diluent Solutions,HW-29086, Sept. 1, 1953.

(72) Burger, L. L., Slansky, C. M. , Density and Viscosity of Solutions in the TBP Process for Uranium Recovery, HW-15233, Nov. 29, 1949.

(73) Burger, L. L. , Analytical Applications of Refractive Index, HW-23228, Jan. 9, 1952.

(74) Bushey, A. H., Quarterly Progress Report, Chemistry Unit, Jan. Mar. 1953, HW-27727, April 30, 1953, p. 46.

(75) Estok, G. K. , Wendlandt, W. W. , J. Am. Chem. Soc. 77, 4767 (1955). 
Table XVI lists some physical properties of possible impurities or common reaction products of TBP.

B. Preparation of TBP and other Phosphates

1. Phosphorus Oxychloride Method

The most versatile and successful method of preparation of the tertiary esters utilizes phosphorus oxychloride, $\mathrm{POCl}_{3}$, and alcohol with a base such as pyridine to remove the hydrochloric acid formed! $(66)(76)$

This method is used on both laboratory and industrial scales and gives excellent yields. Presumably this is the method currently employed in industry for TBP manufacture. A modification employed by Murakami ${ }^{(77)}$ used aluminum chloride, zinc chloride or magnesium chloride as a catalyst and an inert gas to remove the hydrochloric acid.

2. Phosphorus Pentoxide and Alcohol

Probably the cheapest method of manufactur of alkyl orthophosphates is by direct combination of alcohol and phosphorus pentoxide or syrupy phosphoric acid. The yield is largely monoand diesters. Attempts to increase the yield of the triester by raising the temperature only result in degradation of the product. Kosolapof ${ }^{(78)}$ reviews this method and lists some 20 references. The mechanis $m$ is apparently the cleavage of the $\mathrm{P}-\mathrm{O}-\mathrm{P}$ chain by alkylation rather than a true esterification, thus accounting for a low yield of the triester.

3. Silver Phosphate Method

An excellent laboratory method is the reaction between silver phosphate and the alkyl halide. (79) An excess of the halide

(76) Karrer; Paul, Organic Chemistry (2nd Ed.), Elsevier Publishing Co., N. Y. (1946) p. 108 .

(77) Murakami, K. , Chemical High Polymers (Japan) 7, 188 (1950) Chem. Abs. 46, 419 i.

(78) Reference (37) p. 220-21.

(79) Reference (37) p. 225. 
TABLE XVI

\section{PROPERTIES OF SOME TBP IMPURITIES}

\begin{tabular}{|c|c|c|c|c|c|}
\hline Compound & Formula & Specific & Aravity & $\underset{{ }_{C}}{\text { Boiling Point }}$ & $\begin{array}{c}\text { Solubility in } \\
\text { W ater }\end{array}$ \\
\hline Butyl alcohol & $\mathrm{BuOH}$ & 0.810 & $20 / 4$ & 117 & $90 \mathrm{~g} / 1$ \\
\hline Butyl nitrate & $\mathrm{BuONO}_{2}$ & 1.048 & $0 / 4$ & 136 & insoluble \\
\hline Butyl nitrite & BuONO & 0.9114 & $0 / 4$ & $75-79$ & -- \\
\hline Dibutyl phosphate & $(\mathrm{BuO})_{2} \stackrel{\|}{\mathrm{P}} \mathrm{OH}$ & 1. 065 & $25 / 4$ & dec. $175 \mathrm{C}$ & $18 \mathrm{~g} / 1$ at $25 \mathrm{C}$ \\
\hline Monobutyl phosphate & $\stackrel{\mathrm{BuO}}{\mathrm{P}}(\mathrm{OH})_{2}$ & 1.220 & $25 / 4$ & dec. $105-110 \mathrm{C}$ & ca. $25 \mathrm{~g} / 1$ \\
\hline $\begin{array}{l}\text { Tetrabutyl } \\
\text { pyrophosphate }\end{array}$ & $(\mathrm{BuO})_{4} \mathrm{P}_{2} \mathrm{O}_{3}$ & 1. 050 & $25 / 4$ & $143-6$ at $.01 \mathrm{~mm}$ & insoluble \\
\hline $\begin{array}{l}\text { Dibutyl } \\
\text { pyrophosphate }\end{array}$ & $(\mathrm{BuO})_{2} \mathrm{P}_{2} \mathrm{O}_{3}(\mathrm{OH})_{2}$ & 1.228 & $25 / 4$ & dec. $165-169 \mathrm{C}$ & -- \\
\hline $\begin{array}{l}\text { Dibutyl } \\
\text { chlorophosphate }\end{array}$ & $(\mathrm{BuO})_{2} \stackrel{\mathrm{O}}{\mathrm{P}} \mathrm{Cl}$ & 1.074 & $25 / 25$ & $\begin{array}{l}103-106 \text { at } 1.5 \mathrm{~mm} \\
132-5 \text { at } 15 \mathrm{~mm}\end{array}$ & hydrolyzes \\
\hline $\begin{array}{l}\text { Butyl } \\
\text { dichlorophosphate }\end{array}$ & $\mathrm{BuO} \stackrel{\mathrm{O}}{\mathrm{P}} \mathrm{Cl}_{2}$ & 1. 2560 & $25 / 4$ & 90 at $17 \mathrm{~mm}$ & hydrolyzes \\
\hline
\end{tabular}


is used. This method is very good for preparation of mixed esters or for preparation of labelled phosphates. ${ }^{(80)}$ Other metal phosphates yield mostly primary esters.

4. Alkoxide Process

A process similar to the phosphorus oxychloride method discussed above employs sodium alkoxide ${ }^{(81)}$ in place of the alcohol and thus avoids the hydrochloric acid problem. The use of aluminum alkoxide, $A 1(O R)_{3}$, in place of sodium alkoxide is the basis of a patent by Bannister. ${ }^{(82)}$

5. Exchange Esterification

The esters of the acids of phosphorus are, in general, alkylating agents and thus are capable of exchanging alkyl groups with alcohols. The reaction

$$
(\mathrm{RO})_{3} \mathrm{PO}+\mathrm{R}^{\mathrm{P}} \mathrm{OH} \longrightarrow(\mathrm{RO})_{2} \mathrm{R}^{\prime} \mathrm{OPO}+\mathrm{ROH}
$$

is favored if $R^{\prime}$ is larger than $R . R^{\prime}$ ONa will increase the rate of reaction ${ }^{(83)}$ and the process can be utilized for the preparation of specific phosphate esters. Noller and Dutton ${ }^{(66)}$ and Berman and Low ry ${ }^{(18)}$ also studied the alkylation reactions.

6. Phosphorus Trichloride and Hydrocarbons

The direct formation of phosphates from phosphorus trichloride and hydrocarbons in the presence of oxygen was described by Clayton and Jensen. ${ }^{(84)}$ Various products result, depending on concentrations and the temperature employed. The trialkyl

(80) Baldwin, W. H., Higgins, C. E., J. Am. Chem. Soc. 74, 2431 (1952). (81) Evans, D. P., Davies, W. C., Jones, W. J., J. Chem. Soc., 1930, 1310. (82) Bannister, W. J., U. S. Patent (1931), Chem. Abs. 25, 3014.

(83) Rueggeburg, Chernock, J. Am. Chem. Soc., 70, $18 \overline{02}$ (1948).

(84) Clayton, Jensen, J. Am. Chem. Soc., 70, 3880 (1948). 
phosphate yield is small. This preparation is essentially the oxidation of phosphites, $(\mathrm{RO})_{3} \mathrm{P}$. A number of different oxidizing agents have been employed, including barium peroxide, vanadium pentoxide, arsenic pentoxide, nitrogen oxides, sulfur trioxide, sulfuric acid, and persulfuric acid. $(85)(86)$

7. Thermal Decomposition of Acid Phosphates (87)

This reaction can be represented by

$(\mathrm{RO})_{2} \mathrm{NaOPO}+2(\mathrm{RO})_{2} \mathrm{P}(\mathrm{O}) \mathrm{OH} \stackrel{300 \mathrm{C}}{\longrightarrow} 2(\mathrm{RO})_{3} \mathrm{PO}+\mathrm{NaO}(\mathrm{HO})_{2} \mathrm{PO}$

It is probably most applicable to preparation of low molecular weight esters.

For a detailed consideration of several of the above mentioned synthetic methods the reader should consult the extensive references listed by Kosolapoff. (38)

C. Purification

The method of large scale production of tributyl phosphate has not been ascertained but is presumed to be method 1. The crude product impurities would be butoxy phosphorus oxychloride, $\mathrm{BuOPOCl}_{2}$; dibutoxy phosphorus oxychloride, $(\mathrm{BuO})_{2} \mathrm{POCl}$; dibutyl and monobutyl phosphates; butyl alcohol and "condensed" products such as the pyrophosphates,

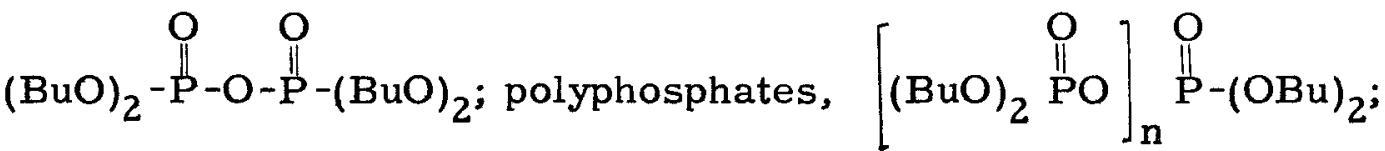
and the metapohosphates, $\left(\mathrm{BuOPO}_{2}\right)_{n}$. It should be noted also that

(85) Chemisch Fabrick Von Heyden A. -G. British Patent, 398659, Chem. Abs. 28, 13625 (1934).

(86) Whitmore, F. C., Organic Chemistry, New York: D. Van Nostrand (1937) p. 173.

(87) Victor Chem. Co. , U. S. Patent -2, 410, 118 (1946). 
the product tributylphosphate is not stable to many of the reagents employed in its synthesis. Thus phosphorus oxychloride, $\mathrm{POCl}_{3}$, reacts with TBP to give intermediate esters; e.g., $\mathrm{BuOPOCl}_{2}$ 。 Similarly, a method of preparation involving $\mathrm{P}_{2} \mathrm{O}_{5}$ can give a high yield of the aforementioned condensed phosphates. These reactions go quite easily, and by controlling the ratio of $\mathrm{P}_{2} \mathrm{O}_{5}$ to TBP one can actually use this method to produce condensed phosphates of the stoichiometric structure. ${ }^{(3)}$ A common property of the condensed phosphates is their ease of hydrolysis leading to butyl acid orthophosphates. The partially esterified $\mathrm{POCl}_{3}$ hydrolyses even more easily. These reactions are considered in Section III-D.

Other compounds that have been reported present in commercial TBP include dibutyl butyl phosphonate, $(\mathrm{BuO})_{2}-\mathrm{P}-\mathrm{Bu}$. (63)

The hydrolysis products, and hence the condensed phosphates and partially reacted phosphorus oxychloride, can all be removed by water washing if sufficient time is taken. Sodium carbonate or sodium hydroxide solutions are much more effective than water. Distillation at reduced pressure following an aqueous wash should produce nearly pure TBP. However, if care is not taken, varying amounts of butyl alcohol and unhydrolyzed intermediates such as $(\mathrm{BuO})_{2} \mathrm{POCl}$ might still remain. Traces of tetrabutyl pyrophosphate and most of the phosphonates, phosphinates or phosphine oxides, if present, could distill with the TBP. DBP and MBP are not volatile and therefore would be separated. (Traces of phosphonates, phosphinates and phosphine oxides are not objectionable from a solvent extraction point of view, although their hydrolysis products would be.) Steam stripping from dilute caustic has been suggested for removing butyl alcohol. (11) A one hour treatment with steam and a five-fold

(88) Gerrard, W., J. Chem. Soc., 1940, 1464。 
volume of 0.4 per cent sodium hydroxide removed all the alcohol and also reduced the acidity of crude TBP to a negligible value. Distillation of crude ester mixture over excess alkali is the basis of a patent assigned to the Food Machinery and Chemical Corporation. (89)

Distillation of TBP over solid sodium carbonate was studied by Lane $^{(2)}$ who concluded that such a distillation did not produce purer TBP than straight distillation but did eliminate "bumping," thus providing better control. Lane's other comments in regard to the distillation included: (1) distillation at 10-15 $\mathrm{mm} \mathrm{Hg}$ pressure $(\sim 150 \mathrm{C})$ is satisfactory after the TBP has been washed, (2) distillation of crude TBP at greater than $100 \mathrm{C}$ causes further decomposition, and (3) the acid decomposition products-DBP - for example, cause further TBP degradation. Decomposition during distillation is also discussed by Lanham and Reilly. (28) Another method of purification used by Lane consists of passing the TBP through a 12 in. $x 1 / 2$ in. column filled with calcium hydroxide. This dries the TBP and reduces the acidity to zero, and is claimed to be more effective than the anion exchange resin, "Amberlite IRA-400," which has also been used. The separation of the butyl acid phosphates by ion exchange was examined by Baldwin and Higgins. (20)(61)

While distillation at reduced pressure is probably the most efficient method of purification of TBP and other tertiary esters, it should be noted that several of the reactions discussed in this section as well as pyrolysis may occur during the distillation step. The vapor pressures of some typical impurities are listed elsewhere in the Appendix.

D. Aqueous Phase Hydrolysis of Other Phosphate Esters The following information is compiled from a comprehensive literature search on the hydrolysis reactions of other phosphate esters. It is

(89) U. S. Patent, Chem. Abs. 44, 3005. 
included here to support the data for TBP.

One of the earliest studies of organic phosphate hydrolysis was made by Cavalier ${ }^{(90)}$ who studied the "saponification" of $\mathrm{PO}_{4} \mathrm{R}_{3}$, $\mathrm{PO}_{3} \mathrm{R}_{2} \mathrm{H}$ and $\mathrm{PO}_{4} \mathrm{RH}_{2}$ where $\mathrm{R}$ was methyl (I) ethyl (II) and propenyl (III). These results are included in Table XXI and can be summarized briefly: (1) In $\mathrm{H}_{2} \mathrm{O}$ at $88 \mathrm{C}$, the hydrolysis rates were III > I > II. (2) Hydrolysis rates of the triester were 10 to 20 times as rapid as those of the diester; hydrolysis rates of the monoesters were slightly faster than those of the diesters. (3) The hydrolysis rate of the triester was more rapid with a base than with water, whereas the $\mathrm{di}$ - and monoesters were stable to bases at $90 \mathrm{C}$. (4) The rates at $88 \mathrm{C}$ were 100 times faster than at $44 \mathrm{C}$. Tennessee Eastman Corp. lists for triethyl phosphate 0.033 per cent per hour at $50 \mathrm{C}$ (91) $^{(91 i m m e r}$ and Burch ${ }^{(92)}$ studied the effect of $2 \underline{N}$ sodium hydroxide and $2 \underline{N}$ sulfuric acid on the hydrolysis rates of the ethyl and propyl esters. Their data are shown in Table XVII.

With caustic, only the triester hydrolyzed; the half life appears to be about six hours if first order kinetics are assumed. This corresponds to about twelve per cent per hour or ten times faster than with pure water at the same temperature (Cavalier at $88 \mathrm{C}$ ). Plimmer and Burch made no kinetic calculations. However, one may assume that the hydrolysis in 1 M sulfuric acid proceeds according to the equations

$\mathrm{TEP} \stackrel{\mathrm{k}_{1}}{\longrightarrow} \mathrm{DEP}+\mathrm{ETOH} \stackrel{\mathrm{k}_{2}}{\longrightarrow} \mathrm{MEP}+\mathrm{ETOH} \stackrel{\mathrm{k}_{3}}{\longrightarrow} \mathrm{H}_{3} \mathrm{PO}_{4}+\mathrm{ETOH}$, with each step first order with respect to the ester. *

(90) Cavalier, J., Compt. Rend. 127, 114-5 (1898).

(91) Tennessee Eastman Corp., "Triethyl Phosphate" Industrial leaflet. (92) Plimmer, R. H. A., Burch, W. J. N., J. Chem. Soc., 1929, 279, 292.

* Following the convention adopted with TBP and derivatives, the alkyl groups are represented by the first letter of the radical name, while mono- and diare abbreviated $M$ and $D$, respectively. $P$ indicates orthosphosphate. 
TABLE XVII

REACTIONS OF PHOSPHATE ESTERS

WITH SODIUM HYDROXIDE AND WITH SULFURIC ACID

Concentration $5 \mathrm{~g}$ ester $/ 1$

Source - Plimmer and Burch $(92)$

\begin{tabular}{|c|c|c|c|}
\hline Compound & $\begin{array}{l}\text { Reflux Time } \\
\text { at } 90 \mathrm{C} \\
\end{array}$ & \multirow[b]{2}{*}{$2 \mathrm{M} \mathrm{NaOH}$} & \multirow[t]{2}{*}{$\begin{array}{l}\text { Moles alco } \\
\text { per mo }\end{array}$} \\
\hline \multirow{5}{*}{$\begin{array}{l}\text { Ba diethyl phosphate } \\
\text { Ba dipropyl phosphate } \\
\text { Triethyl phosphate }\end{array}$} & & & \\
\hline & 8 to $96 \mathrm{hrs}$. & & No $h$ \\
\hline & 8 to $96 \mathrm{hrs}$. & & No hy \\
\hline & 15 hrs. & & 0.79 \\
\hline & 30 & & 0.92 \\
\hline \multirow{3}{*}{ Ba diethyl phosphate } & & $1 \underline{\mathrm{M} \mathrm{H}_{2} \mathrm{SO}_{4}}$ & \\
\hline & 20 & & 0.045 \\
\hline & 48 & & 0.086 \\
\hline \multirow{5}{*}{ Ba dipropyl phosphate } & 144 & & 0.53 \\
\hline & 216 & & 0.82 \\
\hline & 386 & & 1.87 \\
\hline & 48 & & 0.275 \\
\hline & 96 & & 0.525 \\
\hline \multirow[t]{5}{*}{ Triethyl phosphate } & 8 & & 0.84 \\
\hline & 48 & & 1.12 \\
\hline & 120 & & 1.4 \\
\hline & 240 & & 1.8 \\
\hline & 360 & & 2.5 \\
\hline
\end{tabular}


The total alcohol may then be shown equal to

$$
\begin{aligned}
\text { EtOH }_{t} & =3 A_{o}-A_{o}\left[3+2 \frac{k_{1}}{k_{2}-k_{1}}+\frac{k_{1} k_{2}}{\left(k_{1}-k_{3}\right)\left(k_{1}-k_{2}\right)}\right] e^{-k_{3} t}, \\
& +A_{o}\left[2 \frac{k_{1}}{k_{2}-k_{1}}-\frac{k_{1} k_{2}}{\left(k_{2}-k_{3}\right)\left(k_{2}-k_{1}\right)}\right] e^{-k_{2} t}-A_{0}\left[\frac{k_{1} k_{2}}{\left(k_{3}-k_{1}\right)\left(k_{3}-k_{2}\right)}\right] e^{-k_{3} t},
\end{aligned}
$$

where $A_{0}$ is the initial TEP concentration. A similar but simpler expression applies to the reaction which begins with diethyl phosphate (DEP). The data of Table XVII for the ethyl phosphates can be fitted by $\mathrm{k}_{1}=0.15 \mathrm{hr}^{-1}, \mathrm{k}_{2}=.003 \mathrm{hr}^{-1}$ with an uncertainty of about 30 per cent. All that can be said concerning $k_{3}$ is that it is greater than $\mathrm{k}_{2}$ and much less than $\mathrm{k}_{1}$. It is interesting that the rate constant for the first step, $k_{1}$, is about the same as that for the reaction in 2 M sodium hydroxide. The data for TBP, Table V, may be compared here. A faster rate for alkaline hydrolysis than for acid hydrolysis was indicated in the latter case.

Hochwalt ${ }^{(93)}$ studied the stability of a five per cent solution of a mixture of DEP and monoethyl phosphate (MEP) in $\mathrm{H}_{2} \mathrm{O}$ at $25 \mathrm{C}$. These data, presented in Table XIX, suggest that $\mathrm{k}_{2}$ (DEP $\rightarrow$ MEP step) is about $3.5 \times 10^{-4} \mathrm{hr}^{-1}$. Although $\mathrm{k}_{3}$ cannot be evaluated with any certainty (since the data for MEP and $\mathrm{H}_{3} \mathrm{PO}_{4}$ are in some disagreement) a value of about $1.5 \times 10^{-4}$ fits the MEP concentrations. Thus, Hochwalt's data show $\mathrm{k}_{2}>\mathrm{k}_{3}$ in contrast to the previously mentioned results, and any reasonable value of the activation energy (e. g., 10-20 kcal) would yield rates at $50 \mathrm{C}$ or $88 \mathrm{C}$ much higher

(93) Hochwalt, C. A., et al. , Ind. Eng. Chem., 34, 20 (1942). 
than the previous data show. As will be seen later, comparison of rates in water solution is difficult because of the change of $\mathrm{pH}$ as hydrolysis progresses. Hochwalt's five per cent solution is actually quite acid.

Drushel ${ }^{(94)}$ studied the primary hydrolysis of several simple and mixed phosphate esters. In $0.1 \mathrm{M}$ hydrochloric acid a trimethyl phosphate solution gave rate constants $\mathrm{k}_{1}=1.6 \times 10^{-3} \mathrm{hr}^{-1}$ at $25 \mathrm{C}$ and $3.2 \times 10^{-2} \mathrm{hr}^{-1}$ at $100 \mathrm{C}$, corresponding to an activation energy of $12.7 \mathrm{kcal}$. The methyl phosphate hydrolyzed four times faster than the ethyl ester.

In the region between the strong acid hydrolysis and alkaline hydrolysis the picture has been clarified by the work of Desjorbet. ${ }^{(56)}$ A study of the hydrolysis rate of monoethyl phosphate in water at $100 \mathrm{C}$ as a function of $\mathrm{pH}$ revealed that a minimum rate occurred at $\mathrm{pH}=1$. As the $\mathrm{pH}$ was raised to 4 , the rate increased. At about $\mathrm{pH}=5$, the rate decreased, and became negligible at $\mathrm{pH}=8$. At higher acidities than $\mathrm{pH}=1$, the rate increased very rapidly in $2 \underline{M}$ hydrochloric acid was about eight times faster than in $0.1 \mathrm{M}$ hydrochloric acid, and in $7.5 \mathrm{M}$ hydrochloric acid about 120 times faster. His data show a first order rate constant, $\mathrm{k}_{3}$, of $6.5 \times 10^{-3} \mathrm{hr}^{-1}$ in $0.1 \mathrm{M}$ hydrochloric acid and $0.046 \mathrm{hr}^{-1}$ in 2 M hydrochloric acid. The reactions were followed nearly to completion and the work appears to be carefully done. Desjorbet pointed out that the maximum rate occurred at the point of neutralization of the first hydrogen $(\mathrm{pH}=$ 4 to 5 ) and the negligible rate at the neutralization of the second hydrogen $(\mathrm{pH}=8)$. On the high acid side, the nature of the acid was important. Data taken from Desjorbet's curves are listed in Table XIX.

(94) Drushel, W. H. , Am. J. Sci. 190, 643 (1951). 
TABLE XVIII

HYDROLYSIS OF ETHYL PHOSPHATES

$5 \%$ water solution, $25 \mathrm{C}$

Source - Hochwalt(93)

Per cent $P$ present as:

\begin{tabular}{|c|c|c|c|}
\hline Time, days & Diethyl - & Monoethyl - & Phosphoric Acid \\
\hline 0 & 40.3 & 50.0 & 9.7 \\
\hline 4 & 39.7 & 48.0 & 12.3 \\
\hline 11 & 36.1 & 50.0 & 13.9 \\
\hline 18 & 34.3 & 50.0 & 15.7 \\
\hline 26 & 31.4 & 53.3 & 15.3 \\
\hline 32 & 31.2 & 53.4 & 15.4 \\
\hline 39 & 29.2 & 54.7 & 16.1 \\
\hline
\end{tabular}

TABLE XIX

HYDROLYSIS OF MONOETHYL PHOSPHATE

0.1 M solution, $100 \mathrm{C}$, source Desjorbet ${ }^{(56)}$

(\% Hydrolyzed in 6 hours)

Acid

Acid Conc. : $1 \mathrm{M} \quad 2 \underline{\mathrm{M}} \quad 4 \underline{\mathrm{M}}$

$\mathrm{HI}$

$17 \quad 27 \quad 100$

$\mathrm{HBr}$

$13 \quad 23 \quad 84$

$\mathrm{HC} 1$

$10 \quad 16 \quad 38$

$\mathrm{HNO}_{3}$

$\mathrm{H}_{2} \mathrm{SO}_{4}$

$\begin{array}{lll}6 & 7 & 17\end{array}$

$5 \quad 6 \quad 7$

Desjorbet's work shows that the rates, while generally increasing with acid concentration, are not proportional to it except over small ranges. 
Considerable work has also been done on the hydrolysis of methoxyethyl phosphates and glycerophosphates, $(\mathrm{AO})_{2} \mathrm{P}(\mathrm{O}) \mathrm{OCH}\left(\mathrm{CH}_{2} \mathrm{OH}\right)_{2}$ where $A$ is a hydrogen atom or an alkyl group ${ }^{(95-99)}$ as well as acetyl phosphate ${ }^{(52)}$ and other phosphates of biochemical interest. $(100)$ These studies, in common with those on alkyl esters, show that, (a) the methyl group is more easily removed than a larger one, ${ }^{(95)}$ (b) there is a marked $\mathrm{pH}$ effect on alkaline hydrolysis, $(52)(100)$ and (c) alkaline hydrolysis usually stops at the diester. ${ }^{(94)(95)}$ An apparent anomaly is that organic acids are reported to have a greater catalytic action than strong acids. For example, $1 \underline{M}$ acetic acid produces hydrolysis of glycero dihydrogen phosphate and methyl dihydrogen phosphate at a rate 3 to 4 times more rapid than does 1 M sulfuric acid. $(97)(98)$ In addition to hydrolysis, these compounds containing complex ester groups frequently undergo reactions directly involving those groups.

Ketelaar ${ }^{(101)}$ examined the rates of hydrolysis of the methyl and ethyl $\mathrm{p}$-nitrophenyl phosphates in neutral solution and in alkaline solutions. His study was carried out in 50 per cent acetone solution to increase the solubility, and was concerned with the first stage, the hydrolysis of the tertiary ester. Only the nitrophenyl cleavage was determined. His results indicated a faster reaction as more nitrophenyl $\left(\mathrm{NO}_{2} \mathrm{ph}-\right)$ groups were added; e. g. , the hydrolysis rates for $(\mathrm{ETO})_{2}\left(\mathrm{NO}_{2} \mathrm{phO}\right) \mathrm{PO},(\mathrm{ETO})\left(\mathrm{NO}_{2} \mathrm{phO}\right)_{2} \mathrm{PO}$,

(95) Bailly, O., Gaume, J., Bull. Soc. Chem. 2, 354 (1935); 3, 1396 (1936).

(96) Malengreau, F., Prugent, F., Z. Physiol. Chem. 75, $6 \overline{8}$ (1911).

(97) Fluery, P., Courtois, J., Bull. Soc. Chim. 9, 570 (1942).

(98) Verkade, P. E. , Stoppelenburg, J. C., Cohen, W. D., Rec. Trav. Chim. 59, 886 (1940).

(99) Darmon, M. , Bull. Soc. Chim. 1947262.

(100) Fluery, P., Compt. Rend. 221, 416 (1945).

(101) Ketelaar, J. A., Gersman, H. R., Koopmans, K., Rec. Trav. Chim. 71, 1253 (1953). 
and $\left(\mathrm{NO}_{2} \mathrm{phO}\right)_{3} \mathrm{PO}$ were in the order 0.4,31.5, $20601 \mathrm{~mol}^{-1}$ at $25 \mathrm{C}$ in dilute caustic. * The significance of this may be questioned since the ethyl group may hydrolyze easier than the ph- $\mathrm{NO}_{2}$ group, and in this case he would actually be measuring the rates for the compounds $\left(\mathrm{NO}_{2} \mathrm{phO}\right)-\mathrm{P}(\mathrm{O})(\mathrm{OH})_{2},\left(\mathrm{NO}_{2} \mathrm{phO}\right)_{2} \mathrm{P}(\mathrm{O})(\mathrm{OH})$, and $\left(\mathrm{NO}_{2} \mathrm{phO}\right)_{3}$ $\mathrm{PO}$, a quite different situation. $* *$ The work is interesting from the mechanism standpoint and is mentioned in that section. The activation energy varied from about 12 to $14 \mathrm{kcal}$ for the hydrolysis reactions of the ethyl derivatives and was about $4 \mathrm{kcal}$ for trinitrophenyl phosphate.

Gerrard, Green, and Nutkins ${ }^{(26)}$ refluxed various isooctyl esters of phosphoric acid with potassium hydroxide solution and determined the alcohol produced. The data together with pertinent calculations are shown in Table XX.

Thus, even though an excess of organic may be present, these reactions can probably be treated as aqueous phase reactions. The aqueous phase is saturated at all times; however, as the solubility is not known, a rate constant cannot be calculated. The apparently greater rate for the disooctyl acid phosphate is perhaps a reflection of the much larger solubility of this compound. However, the minor effect produced by solubilizing the triester with ethyl alcohol does not suggest this. Data on this hydrolysis of diisooctyl phsphate are in disagreement with other reports that the dialkyl and monoalkyl esters are completely stable in alkaline solution.

Hydrolysis data for the various alkyl phosphates discussed in this section are listed in Table XXI.

* Ketelaar writes a second order rate constant for the overall reaction, since his work indicated that the hydrolysis was first order with respect to both $\mathrm{OH}^{-}$and ester. In the present paper, where it is not expressly stated, the concentration of acid or base is considered constant and the rate constant given for the ester alone.

**Support for Ketelaar ${ }^{\prime}$ s interpretation is his observation that the analogous compound diethyl nitrophenyl phosphorothioate, "parathion," hydrolyzed to the diethyl phosphorothioate which was stable. 
TABLE XX

HYDROLYSIS OF

ISOOCTYL PHOSPHATE IN POTASSIUM HYDROXIDE SOLUTIONS

R - isooctyl; temperature - boiling point of solution; Source - Gerrard (26)

\begin{tabular}{|c|c|c|c|c|}
\hline Compound & $\begin{array}{l}\text { Conc. Ester, Moles } \\
\text { per Liter Solution* }\end{array}$ & Aq. Phase & Time, hrs. & $\begin{array}{l}\text { Alcohol } \\
\text { Produced, } \\
\quad \text { M }\end{array}$ \\
\hline \multirow[t]{2}{*}{$(\mathrm{RO})_{3} \mathrm{PO}$} & 0.092 & $1 \underline{\mathrm{M} \mathrm{KOH}}$ & 24 & 0.040 \\
\hline & & $2 \mathrm{M} \mathrm{KOH}$ in $\mathrm{EtOH}$ & 27 & 0.050 \\
\hline$(\mathrm{RO})_{2} \mathrm{P}(\mathrm{O}) \mathrm{OH}$ & 0.248 & $1 \mathrm{M} \mathrm{KOH}$ & 28 & 0.21 \\
\hline \multirow[t]{3}{*}{$(\mathrm{RO}){ }_{2} \mathrm{P}(\mathrm{O}) \mathrm{OEt}$} & 0.179 & $1 \underline{\mathrm{M}} \mathrm{KOH}$ & 25 & 0.532 \\
\hline & & $1 \underline{\mathrm{M} \mathrm{KOH}}$ in $\mathrm{EtOH}$ & 24 & 0.054 \\
\hline & & $2 \underline{\mathrm{M} \mathrm{KOH}}$ in $\mathrm{EtOH}$ & 38 & 0.068 \\
\hline
\end{tabular}

*Organic phase probably present. 
TABLE XXI

RATE CONSTANTS FOR THE AQUEOUS HYDROLYSIS OF ALKYL PHOSPHATES

\begin{tabular}{|c|c|c|c|c|c|c|}
\hline Estert & System & Temp, C & $\begin{array}{r}\mathrm{k}_{1}^{*} \\
\mathrm{hr}^{-1}\end{array}$ & $\begin{array}{l}\mathrm{k}_{2} \\
\mathrm{hr}\end{array}$ & $\begin{array}{r}\mathrm{k}_{3} \\
\mathrm{hr}^{-1}\end{array}$ & References \\
\hline TMP & $\overline{\mathrm{H}_{2} \mathrm{O}}$ & 88 & 0.063 & $3.6 \times 10^{-3}$ & $5.6 \times 10^{-3}$ & (90) \\
\hline TMP & $0.1 \underline{\mathrm{MCl}}$ & 100 & 0.131 & -- & -- & (94) \\
\hline TMP & $0.1 \underline{\mathrm{MCl}}$ & 25 & $1.6 \times 10^{-3}$ & -. & - & (94) \\
\hline TMP & $0.5 \mathrm{M} \mathrm{H}_{2} \mathrm{SO}_{4}$ & 100 & -- & -- & $8.8 \times 10^{-3}$ & (97) \\
\hline TMP & 1. $0 \underline{\mathrm{M} H O A C}$ & 100 & -- & -- & 0.016 & (97) \\
\hline TEP & $\mathrm{H}_{2} \mathrm{O}$ & 25 & -- & $3.5 \times 10^{-4}$ & $3.5 \times 10^{-4}$ & (93) \\
\hline TEP & $\mathrm{H}_{2} \mathrm{O}$ & 88 & 0.011 & $1.5 \times 10^{-3}$ & $3.2 \times 10^{-3}$ & $(90)$ \\
\hline TEP & $\mathrm{H}_{2} \mathrm{O}$ & 44 & $1.1 \times 10^{-4}$ & -- & -- & $(90)$ \\
\hline TEP & $\mathrm{H}_{2} \mathrm{O}$ & 50 & $3.3 \times 10^{-4}$ & -- & -- & (91) \\
\hline TEP & $1 \underline{\mathrm{M}} \mathrm{HNO}_{3}$ & 100 & -- & -- & $8.9 \times 10^{-3}$ & (56) \\
\hline TEP & $2 \underline{\mathrm{M}} \mathrm{HNO}_{3}$ & 100 & -- & -- & 0.0125 & (56) \\
\hline TEP & $4 \underline{\mathrm{M}} \mathrm{HNO}_{3}$ & 100 & -- & -- & 0.023 & (56) \\
\hline TEP & $0.001 \mathrm{M} \mathrm{HCl}$ & 100 & -- & -- & 0.0195 & (56) \\
\hline TEP & $0.1 \mathrm{M} \mathrm{HCl}$ & 100 & -- & -- & $6.5 \times 10^{-3}$ & (56) \\
\hline TEP & 2. $0 \underline{\mathrm{M} \mathrm{HCl}}$ & 100 & -- & -- & 0.046 & (56) \\
\hline TEP & 7. $5 \underline{\mathrm{M} \mathrm{HCl}}$ & 100 & -- & -- & 0.825 & (56) \\
\hline TEP & $0.1 \mathrm{M} \mathrm{HCl}$ & 100 & 0.0318 & -- & -- & $(94)$ \\
\hline TEP & $1 \underline{\mathrm{M} \mathrm{H}} \mathrm{SO}_{4}$ & 90 & 0.15 & $3 \times 10^{-3}$ & $3 \times 10^{-3}$ & $(92)$ \\
\hline TEP & $2 \underline{\mathrm{M}} \mathrm{NaOH}$ & 90 & 0.11 & Negligible & Negligible & (92) \\
\hline TPP & $1 \underline{\mathrm{M}} \mathrm{H}_{2} \mathrm{SO}_{4}$ & 90 & -- & $6 \times 10^{-3}$ & -- & (92) \\
\hline
\end{tabular}

+The second letter in the code, M, E or P refers to methyl, ethyl, or propyl, respectively.

*The symbols $k_{1}, k_{2}$, and $k_{3}$ represent the rate constants for the hydrolysis of the triester, diester, and the monoester, respectively.

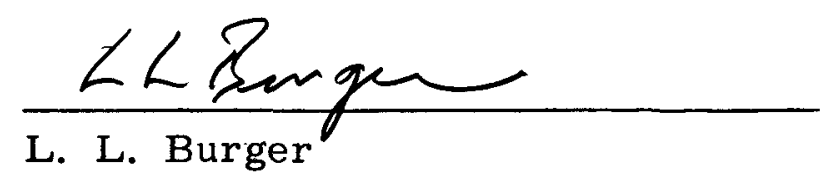

Q. Bromenes 